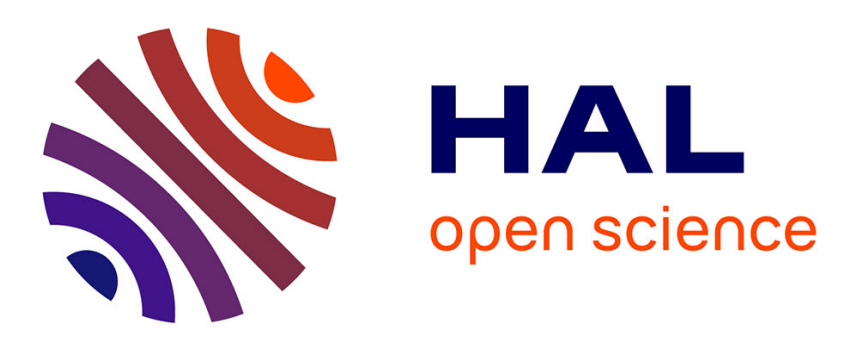

\title{
Overriding plate velocity control on surface topography in 2-d models of subduction zones
}

\author{
Nestor G. Cerpa, Diane Arcay
}

\section{To cite this version:}

Nestor G. Cerpa, Diane Arcay. Overriding plate velocity control on surface topography in 2-d models of subduction zones. Geochemistry, Geophysics, Geosystems, 2020, 21 (4), 10.1029/2019GC008900 . hal-02543277

\section{HAL Id: hal-02543277 \\ https://hal.umontpellier.fr/hal-02543277}

Submitted on 15 Apr 2020

HAL is a multi-disciplinary open access archive for the deposit and dissemination of scientific research documents, whether they are published or not. The documents may come from teaching and research institutions in France or abroad, or from public or private research centers.
L'archive ouverte pluridisciplinaire HAL, est destinée au dépôt et à la diffusion de documents scientifiques de niveau recherche, publiés ou non, émanant des établissements d'enseignement et de recherche français ou étrangers, des laboratoires publics ou privés. 


\title{
Overriding plate velocity control on surface topography in 2-d models of subduction zones
}

\author{
Nestor G. Cerpa ${ }^{1,2}$, Diane Arcay ${ }^{1}$ \\ ${ }^{1}$ Géosciences Montpellier, Université de Montpellier, CNRS, Université des Antilles, Montpellier, France \\ ${ }^{2}$ Géoazur, Université Côte d'Azur, CNRS, Observatoire de la Côte d'Azur, IRD, Valbonne, France
}

\section{Key Points:}

- The topography amplitude and position ontop of the overriding plate are controlled by its kinematics and the plate and interface strengths.

- Changes in overriding plate velocity yield transient strong (rates $\sim 0.1 \mathrm{~mm} / \mathrm{yr}$ ) surface vertical motions from the trench to the arc region.

- The strength of the subducting plate has the strongest impact on the topographic response after a change in overriding plate kinematics.

Corresponding author: Nestor G. Cerpa, nestor.cerpa@gm.univ-montp2.fr 


\begin{abstract}
We study the dynamically-induced flexural topography in subduction numerical mechanical models. We focus on the topographic changes at the overriding plate (OP) surface induced by variations in OP kinematics,particularly when the subducting plate (SP) has a stationary motion after having reached the rigid base of the upper mantle. Our models consist of two visco-elastic plates with free surfaces and an isoviscous mantle. Friction is imposed along the planar subduction interface. We first characterize the main topographic features at a constant OP velocity, using spatial definitions based on geometrical estimations of the volcanic arc position. The models exhibit the formation of a bulge in the forearc area followed landwards by a depression and a smaller second bulge, both bracketing the arc region. The steady-state distance to the trench of these features increase with OP velocity. Their amplitude is affected by the far-field OP tectonic regime which depends on kinematics, and plates and subduction interface strength. We next test the effect of sudden changes in OP velocity. An OP acceleration yields a transient topographic tilt, during which the outer forearc quickly subsides whereas the arc region uplifts, and that is followed by reverse slower motions. An OP slowdown induces opposite motions. The rates of elevation change during the tilt are approximately proportional to velocity variations and mainly sensitive to the SP strength. The rates are higher than $0.1 \mathrm{~mm} / \mathrm{yr}$ for velocity changes higher than $1 \mathrm{~cm} / \mathrm{yr}$. We suggest that topographic accommodations of $\mathrm{OP}$ velocity changes should be considered when quantifying non-isostatic topography.
\end{abstract}

\title{
Introduction
}

Earth's surface topography is the result of multiple overlapping processes. Regional tectonics cause crustal shortening or stretching that is accommodated by isostatic compensation, inducing continuous vertical adjustment motions. Surface erosion and redistribution of surface loads induce bending and affect surficial shaping at short-to-intermediate wavelengths $(\lesssim 100 \mathrm{~km}$ ). Long wavelength vertical deformation, at the other end, has a dynamic origin that is the deep mantle circulation exerting radial stresses at the base of the lithosphere (Cazenave et al., 1989; Forte et al., 1993; Hoggard et al., 2016). The wavelength $(\gtrsim 1000 \mathrm{~km})$ and the amplitude $(\lesssim 1 \mathrm{~km})$ of such a mantle-induced dynamic topography, commonly referred to as "dynamic topography", is controlled by the extent of deep density anomalies forcing the mantle to flow (e.g. sinking slabs), and its rate of change may be of the order of 0.001-0.01 mm/yr (Braun, 2010; Arnould et al., 2018), although some studies propose values up to $0.1 \mathrm{~mm} / \mathrm{yr}$ (e.g., Briaud et al., 2020).

At subduction zones, dynamic topography has been invoked to explain large-scale vertical deformations in distal regions relative to the trench, as for instance the tilting of entire continents (Mitrovica et al., 1989; Gurnis, 1993; Shephard et al., 2010) and anomalous subsidence of foreland (Dávila \& Lithgow-Bertelloni, 2013) and back-arc basins (Husson, 2006). Closer to the trench (from forearc to the proximal back-arc region) the subduction of a dense oceanic lithosphere is expected to deflect the overriding plate at intermediateto-long wavelengths, and thus to affect topography, by (Davies, 1981; Zhong \& Gurnis, 1994): 1) the interplate force (decomposed by some authors into a shear force at the subduction interface and a "trench-suction" force normal to the interface (e.g., Chen et al., 2017), which transmits part of the slab pull and mantle-viscous support to the surface via the slab guide (Elsasser, 1969) and 2) the viscous shear and traction forces exerted by the mantle corner flow on the overriding plate (McKenzie, 1969). Since the overriding plate deflection near the trench is driven by the dynamics of the subduction system while not being solely induced by the traction by mantle flow (i.e, differs from the common definition of dynamic topography), in what follows, we refer such a deflection to as dynamically-induced topography. Note that the interplate force can also cause crustal deformation and impact surface isostatic topography at the same wavelength as the dynamicallyinduced topography (e.g., Sobolev \& Babeyko, 2005). 
Deciphering deep solid-Earth dynamics from surface observations may be obscured by our relatively little understanding of the causes and consequences of changes in the dynamics of natural subduction systems. It is nonetheless thought that these changes are expressed in the temporal evolution of the non-isostatic topography. For instance, Henry et al. (2014) suggested that the arrival of bathymetric anomalies at subduction trenches may be a prime control on forearc deformation and may partly explain the uplift of the South-American western coast in the Quaternary. Regional effects, such as farfield kinematical changes, are also possible contributors (see e.g., Martinod et al., 2016). In addition, there are numbers of examples in Nature where topography of the arc/backarc regions has dramatically changed at spatial scales of 100-1000 km and over timescales of a few Myrs, with the possibility of deep (dynamic) driving mechanisms. The eastern Alboran arc region, linked to the eastwards subduction of the Alboran slab, is one of them. It is thought to have undergone a short period of uplift (less than 2 Myrs) that has caused the closing of the marine gateways responsible for the Messinian salinity (Duggen et al., 2003). In the Caribbean, the extinction of the Cretaceous arc (the Aves Ridge at presentday) might have been followed by a period of regional uplift (Lallemand \& Lebrun, 2017), that might have lasted for only a few Myrs (Iturralde-Vinent \& MacPhee, 1999; Marivaux et al., 2020) and might have resulted from a sudden change in the dynamics of the subducting slab (Allen et al., 2019). The growing evidences of the role played by changes in subduction dynamics in the building of non-isostatic topography, makes the quantification of their relationship an area of active research.

The models of isolated subduction zones where slab pull is the only driving force of the system ("free" subduction models) suggest that the buoyancy of the subducting slab and its strength are the prime controls on subduction dynamics (Funiciello et al., 2003; Bellahsen et al., 2005; Schellart, 2008; Ribe, 2010; Garel et al., 2014; Holt et al., 2015; Alsaif et al., 2020). It has indeed been argued that subducting plate motions in Nature could be explained by the effect of slab pull alone (Goes et al., 2011). In contrast, the present-day motions of overriding plates require other driving mechanisms (e.g., Lallemand et al., 2008). In that sense, the kinematics of the overriding plate may be considered as an external control on the dynamics of a subduction system, thereby controlling for instance the deformation of the back-arc (Heuret \& Lallemand, 2005). Further, modeling studies show that the friction at the subduction interface, partly controlled by the amount of sediments entering at the trench, influences subduction velocity and overriding plate deformation (Hassani et al., 1997; Arcay et al., 2008; Gerardi \& Ribe, 2018; Behr \& Becker, 2018). In particular, both the overriding plate velocity and the friction at the subduction interface may affect surface topography (see e.g., Hampel \& Pfiffner, 2006; Martinod et al., 2016). It has further been proposed that the strength of the plates interface may be a prime control on the variety of observed tectonic regimes and associated topography (Lamb \& Davis, 2003; Sobolev \& Babeyko, 2005).

On the basis of plate kinematic reconstructions showing that the speed of plates has often varied over geological timescales (e.g., Zahirovic et al., 2015), Guillaume et al. (2018) conducted laboratory experiments to investigate the dynamics of analog subduction systems when the overriding plate motion varies. In a subduction model that has reached steady-state, when a sharp variation in overriding plate kinematics is imposed, the models exhibit a transient stage of departure from the initial steady-state that lasts approximately a few dozens of Myrs before reaching a new steady-state. Cerpa et al. (2018) showed that during this stage of accommodation to new kinematic boundary conditions, the variation in slab dip induces a tectonic pulse, that is a pulse in horizontal stresses within the overriding plate, through the interplate coupling. The authors hypothesized that this mechanism might have triggered some of the observed shifts in overriding plate tectonics (e.g., Clark et al., 2008). The same mechanism may affect topography (Martinod et al., 2016) but has yet to be quantified. 
Here, using 2-d numerical mechanical models of subduction dynamics, we assess the spatio-temporal evolution of the main dynamically-induced topographic features (of wavelength $\sim 100 \mathrm{~km}$ ) at the surface of the overriding plate. We place an emphasis on the impact of changes in overriding-plate kinematics on vertical motions. The manuscript is structured as follows. In Section 1, we describe the modeling approach. In Section 2, we present our main results. We first report models in which the overriding plate moves at a constant rate. We describe the general evolution of these models in terms of kinematics, dynamics and resulting overriding plate topography. We investigate the dependence of the steady-state topography on kinematical and rheological parameters. Next, we address the evolution of overriding-plate topography in models where the plate moves at a variable rate. We highlight the peak vertical motions in the forearc and the arc regions and their dependence to key model parameters.

\section{Model setup}

We assume that the lithospheric plates behave as Maxwell viscoelastic solid bodies and that the mantle behaves as a Newtonian fluid (Bonnardot et al., 2008; Morra \& Regenauer-Lieb, 2006; Capitanio et al., 2007; Cerpa et al., 2014, 2015). The governing equations and our numerical approach have been described in Cerpa et al. (2014) and are summarized in the Supplementary Information.

Our 2-d cartesian model set-up consists of two 70-km thick viscoelastic plates (overriding plate: OP; subducting plate: $\mathrm{SP}$ ) with stress-free top surfaces and an isoviscous upper mantle (Fig. 1). A plate-mantle density contrast of $50 \mathrm{~kg} \mathrm{~m}^{-3}$ is enforced at the base of the lithospheric plates (Table 1 ). The model has thus roughly the characteristics of an intermediate-age oceanic lithosphere $(\sim 40 \mathrm{Ma})$ entering at the subduction trench. All other model rheological parameters are given in Table 1, including the parameters that are tested in this study : the strength of the subduction interface by varying its friction coefficient $\mu$ and the strength of the plates by varying the viscosity of the overriding plate $\left(\eta_{o p}\right)$ and of the subducing plate $\left(\eta_{s p}\right)$. The resistance of both plates to deformation is expected to modulate the response of the system to variations in OP motion, as previously shown by Cerpa et al. (2018) for the accommodation of slab dip. We consider viscosities in the range $3 \times 10^{23}$ to $3 \times 10^{24} \mathrm{~Pa}$ s which lead to Maxwell relaxation times roughly comprised between 0.1 and 1 Myr. The subduction interface in (thermo)mechanical models of subduction zones has been commonly treated as a layer of finite width and of very weak strength relative to the surrounding lithosphere (e.g., Duarte et al., 2013; Garel et al., 2014; Hertgen et al., 2020). A very weak shear strength along the subduction interface may result from the presence of fluids and sediments (Behr \& Becker, 2018). It has been invoked to enable initiation and evolution of single-sided subduction (Gerya et al., 2008; Crameri \& Tackley, 2015), and to reproduce plate-tectonic like velocities (Sobolev \& Brown, 2019). In our case, the lubricating processes on the subduction interface are accounted for by setting a relatively low $\mu$ (0.01-0.06) to the dry-contact surface between the plates (See Text S1 in the Supp. Info.).

In all models, the subducting plate is initially pushed by a piston that moves at a constant velocity of $1 \mathrm{~cm} / \mathrm{yr}$. During this initial stage, the subducting plate and the piston are held together because of the contact force that they apply on each other, roughly equivalent to a lithostatic suction. When the slab pull overcomes the latter force, the plate and the piston are separated. The subducting plate becomes "free", i.e. the piston no longer drives its motion and a lithostatic pressure is applied on its trailing edge. A far-field velocity $\left(v_{o p}\right)$ is applied at the trailing edge of the overriding plate, unless otherwise stated. This velocity is either constant through time in the models or varied once. Those models are referred to as "SP-free models". In a few models, referred to as "free models", the overriding plate is also initially pushed with a piston and then let free to move. Throughout the manuscript, positive values of velocities denote trenchward motion. 
Table 1. Model parameters. Light-gray and dark-gray rows correspond to the rheological and kinematic parameters, respectively, which are varied in the study. The values given in the last column of the colored rows are the reference parameters.

\begin{tabular}{l|c|c|c|}
\hline Parameters & Description & Unity & Value \\
\hline$\Delta \rho$ & Plates-mantle density contrast & {$\left[\mathrm{kg} \mathrm{m}^{-3}\right]$} & 50 \\
$E$ & Young modulus & {$[\mathrm{Pa}]$} & $10^{11}$ \\
$\nu$ & Poisson ratio & & 0.25 \\
$\eta_{s p}$ & SP viscosity & {$[\mathrm{Pa} \mathrm{s}]$} & $10^{24}$ \\
$\eta_{o p}$ & OP viscosity & {$[\mathrm{Pa} \mathrm{s}]$} & $10^{24}$ \\
$\mu$ & Interplate friction & 0.01 \\
$\eta_{m}$ & Mantle viscosity & {$[\mathrm{Pa} \mathrm{s}]$} & $10^{20}$ \\
$v_{\text {op }}$ & OP far-field velocity & {$[\mathrm{cm} / \mathrm{yr}]$} & 4 \\
\hline \multicolumn{2}{|c|}{${ }^{\dagger}$ The plates-mantle density contrast it set at the bottom of the } \\
plates at $t \quad=\quad$ 0. Because of elasticity, the lithospheric plates are \\
compressible and a model for mantle compressibility is assumed, as \\
described in Hassani et al. (1997).
\end{tabular}

The upper mantle is passive with open sidewalls on which a lithostatic pressure applied. We consider a no-slip boundary condition at its base, modeling thus slab stagnation at the mantle transition zone. Slab stagnation is observed in number of present-day subduction zones and might be a common stage in the evolution of most subduction systems (Fukao \& Obayashi, 2013; Goes et al., 2017). Also, forcing a perfect slab anchorage at the base of the upper mantle helps the system to reach a quasi-steady state and permits to isolate the sole effects of changing the kinematical boundary conditions (Cerpa et al., 2018).

\section{Results}

\subsection{Topography at constant overriding plate velocity}

\subsubsection{Comparison of the dynamics of free and SP-free models}

We first describe the dynamical and kinematic evolution of a 2-d subduction system where the overriding plate advances at the constant reference velocity of $4 \mathrm{~cm} / \mathrm{yr}$ (reference OP velocity). SP and OP viscosities are set to the reference values. Two cases for interplate friction are studied : $\mu=0.01$ (reference model) and $\mu=0.04$. These two cases are also systematically investigated in the following sections. To help the analysis, here, we compute additional "free models".

Figure 2a shows the evolution of kinematics in the free model with $\mu=0.01$ (Movie S1). The two plates are initially pushed against each other by two pistons. During this initial stage, indicated as the "subduction initiation" phase, the plates move at the same velocity as the pistons (i.e. at $1 \mathrm{~cm} / \mathrm{yr}$ ). When the plates become free, a first phase of plates acceleration is observed (for the subducting plate from $t=16 \mathrm{Myr}$ to $t=22 \mathrm{Myr}$ ). This phase, hereafter referred to as "slab sinking" phase, ends when the slab tip first reaches the rigid bottom of the upper mantle at $t \simeq 22$ Myr. A transitory "stabilization" phase follows during which the slab interacts with the impermeable 660-km boundary. The slab successively abruptly decelerates and then slowly re-accelerates while moving forward and backwards, respectively. A fourth and last phase of "quasi-steady state" where little variation in plates velocity occurs after 50 Myr. The SP-free model (Fig. 2b and Movie S2) shows a similar partitioning in four phases that is visible in the evolution of SP kine- 
matics. In particular, a quasi-steady state is also reached earlier, after 40 Myr. Note that in both the free and SP-free models, the subducting plate moves at a relative low velocity $\left(v_{s p}<1 \mathrm{~cm} / \mathrm{yr}\right)$ due to the perfect slab anchoring at the base of the upper mantle. Figure 2e exhibits the far-field horizontal non-lithostatic force $F_{x x}$ within the overriding plate through time in the SP-free model (Cerpa et al., 2018). The slower overriding plate in the SP-free model (imposed $v_{o p}=4 \mathrm{~cm} / \mathrm{yr}$ ) than its "free motion" (OP velocity of about $6 \mathrm{~cm} / \mathrm{yr}$ ) provokes far-field extension in the plate during the quasi-steady state phase.

Figure 2c,d illustrates the kinematics of similar models but with $\mu=0.04$. Compared to the models with a lower friction coefficient at the subduction interface, the stage of subduction initiation is longer in the free models with $\mu=0.04$. The slab tip first reaches the $660-\mathrm{km}$ boundary at a later time (at $t \simeq 31 \mathrm{Myr}$ in the free-model) and the quasi-steady state starts only after 70 and $50 \mathrm{Myr}$ in the free-model and the SP-free model, respectively. As expected, the motion of the subducting plate is slower during the slabsinking phase in the models with a higher $\mu$. This is also observed during the quasi steadystate phase of the free-models. The effect of interplate friction coefficient on $v_{s p}$ during the latter phase is negligible in the SP-free model. In the latter model, the overriding plate is pushed faster during the steady-state than its "free motion" (OP velocity of about $2.2 \mathrm{~cm} / \mathrm{yr}$, Fig. 2b) which leads to far-field compression within the plate (Fig. 2f).

\subsubsection{Topography in reference models}

We now study the topography of the overriding plate in SP-free models with a constant $v_{o p}$, by extracting topographic profiles (i.e. the shape of the free-top surface) in those models at several stages. In the following, the elevation $z$ is defined as the vertical position relative to the mean vertical position of the top of the overriding plate over a distance of $200 \mathrm{~km}$ from the trailing edge (Fig. 1), that is over a region unaffected by the dynamically-induced topography. Negative values of elevation are downwards, and those are sometimes referred to as depth (depth is positive for negative vertical position). The horizontal position $x$ relative to the trench is referred to as location. The use of "behind" for describing a location means farther from the trench.

Moreover, for each model, we calculate the position of an idealized volcanic arc at the surface of the overriding plate. Our definition is purely geometrical and corresponds to the region that overlies the top of the subducting slab by a vertical distance comprised between 70 and $180 \mathrm{~km}$, as observed in nature (Syracuse \& Abers, 2006).

Figure 3a,b exhibits the OP surface elevation $z$ (solid lines) for the reference model (i.e. with $\mu=0.01$ ). The circles bracket the estimated position of the volcanic arc.

The early phase of slab sinking through the upper mantle (cyan line) is characterized by a high bulge reaching up to $2.5 \mathrm{~km}$, that follows a deep trench $(z \simeq-9 \mathrm{~km})$. A surface depression is located behind this first bulge at horizontal distances from the trench between 200 and $400 \mathrm{~km}$. It is predicted to host the arc which may lie in the region situated at $180-300 \mathrm{~km}$ from the trench. A second bulge (at $\simeq 450 \mathrm{~km}$ from the trench), much smaller in amplitude than the first one is observed. These are followed by the relatively flat inland region of the overriding plate.

During the quasi-steady state phase, the surface elevation evolves relatively little, and can be discussed in terms of a time-averaged profile (red line). The first bulge is less prominent than during the slab-sinking phase, reaching only $\simeq 0.5 \mathrm{~km}$. The depression is deeper (lowest point at $z \simeq-1$ to $-1.5 \mathrm{~km}$ ) than in the first phase. The rear part of this depression and the second bulge, now overlaps with the estimated position of the arc (between 180 and 300 from the trench). The elevation of the top of the latter bulge is $\simeq 0.25 \mathrm{~km}$. Note that given the relaxation time in this model $(\sim 0.3 \mathrm{Myr})$, the quasisteady state topography that develops mainly results from the viscous behavior of the plates. 
Figure $3 \mathrm{c}, \mathrm{d}$ shows elevation profiles for the model with reference $v_{o p}$ and $\mu=0.04$. The slab-sinking phase is also characterized by a prominent first bulge, although its height is only half of that in the case with $\mu=0.01$. During the quasi-steady state phase, the elevation of this bulge reaches only $-0.25 \mathrm{~km}$ and is thus deeper than in the case with a lower $\mu$. The height of the second bulge is equivalent in the two models with different values of $\mu$. The arc lies between the rear part of the depression and the rear of the second bulge.

The OP topography during the slab sinking phase, and its dependence on plates and mantle mechanical parameters have been analyzed in number of previous studies (Shemenda, 1993; Hassani et al., 1997; Hampel \& Pfiffner, 2006; Bonnardot et al., 2008; Crameri et al., 2017; Dasgupta \& Mandal, 2018). Hence, here we focus on the OP topography after the first interaction between the slab and the base of the upper mantle, when the system has reached a quasi-steady state.

\subsubsection{Effect of kinematic parameters and OP tectonic regime on steady- state topography.}

Figure 4a,b shows the time-averaged quasi-steady state topographic profiles in models with applied OP velocities (and $\mu=0.01$ ) and that in the equivalent free model (see Fig. 2a), as well as the associated time-averaged far-field non-lithostatic horizontal force within the overriding plate in models with imposed OP kinematics. An imposed OP velocity of about 5-6 cm/yr induces a "neutral" OP tectonic regime, that is a regime where horizontal stresses far from the trench are close to zero. The OP topography in this regime is similar to that in the free model. They exhibit the flattest topography compared to that in the other models, with the lowest vertical drop from the first bulge to the depression. Further, the bottom of the overriding plate near the subduction interface is relatively flat (see Fig. S2b in the in the Supplementary Information). These observations suggest a negligible overall pull-down of the trenchward-most region of the overriding plate by traction at the subduction interface in the neutral-tectonic regime. From this regime, decreasing $v_{o p}$ (i.e. increasing extension) mainly increases the amplitude of the arc depression while the bottom of the overriding plate is pulled-down by the interplate force normal to the plates interface (Fig. S2a). In contrast, increasing $v_{o p}$ (i.e. increasing compression) mainly provokes the growth of the forearc bulge and the rise of the bottom of the overriding plate near the plates interface.

These observations are consistent with the studies by Shemenda (1993) and Hassani et al. (1997) who conducted analog and numerical models to study the general OP topography in the context of both compressional and extensional OP tectonic regimes, assuming elastic plates. These authors showed that a plate-mantle positive density contrast, i.e when the subducting plate is denser than the surrounding mantle and provokes OP extension, tended to drag downwards the forearc region and favored the formation of a surface depression. A negative density contrast tended to prevent the formation of the depression and to rise the forearc. Our models show similar trends but the OP tectonic regime arises here from the differential between the imposed motion of the plate and the velocity that it would have in an equivalent free-model.

The profiles for models with $\mu=0.04$ (Fig. 4c) show that an increased shear force on the subduction interface, disturbs the relationship between the far-field OP tectonic regime and the topography near the trench observed at low (negligible) interplate friction coefficient. The topography in the free model with $\mu=0.04$ and in the equivalent $v_{o p}$-imposed models near the neutral regime (i. e. with $v_{o p} \simeq 2 \mathrm{~cm} / \mathrm{yr}$ ) show a prominent depression. This suggests that although little traction is exerted by the subducting plate on the overriding plate, the relatively high shear force on the plate interface is sufficient to induce a downdip drag of the OP trenchward-most region (also visible in the shape of the bottom of the overriding plate in Fig. S2). As a matter of fact the low- 
est crest-to-crest amplitude of first bulge-to-depression are obtained in the compressive regime (with an $\mathrm{OP}$ velocity of about $5 \mathrm{~cm} / \mathrm{yr}$ ) when the trench-normal interplate compressive force is high enough to counter-balance the effect of the friction at the plates interface.

\subsubsection{Effect of rheological parameters on steady-state topographic fea- tures}

We now assess the first-order influence of rheological parameters $\left(\mu, \eta_{o p}, \eta_{s p}\right)$ on the topography at steady-state by quantifying the location $(x)$ and elevation $(z)$ of the three main topographic features (two bulges and one depression). We systematically investigate their spatial distribution in models with a constant OP velocity spanning the range $2-8 \mathrm{~cm} / \mathrm{yr}$. The parameters of the 41 models (26 shown here) used for the analysis are summarized in Table S1 in the Supplementary Information.

The described positions of the bulges and the depression are that of their top and bottom, respectively. Because these positions are time-averaged during the quasi-steady state, we sometimes referred them to as steady-state location and steady-state elevation. The results are displayed in Fig. 5.

\subsubsection{Models with reference rheological parameters:}

The models with reference rheological parameters $\left(\eta_{s p}=\eta_{o p}=10^{24} \mathrm{~Pa} \mathrm{~s}\right.$ and $\mu=0.01$, respectively) are indicated by dark blue circles in Fig. 5 . The location of the lower-end and even more that of the upper-end estimation of arc position display a net linear dependence on $\mathrm{OP}$ velocity. This results from the strong relationship between OP velocity and slab dip at depths $\geq 100 \mathrm{~km}$ (Cerpa et al., 2018) (see also Supp Info - Fig. $\mathrm{S} 1$ ). The location of the first bulge $x_{F B}$ shows little dependency on $v_{o p}$ (Fig. $5 \mathrm{a}$, see also 4a), remaining at a distance of around $100 \mathrm{~km}$ from the trench for $v_{o p} \leq 7 \mathrm{~cm} / \mathrm{yr}$ and slightly increasing when the $\mathrm{OP}$ is in compression to $\simeq 150 \mathrm{~km}$ at $v_{o p}=8 \mathrm{~cm} / \mathrm{yr}$. The lower-end estimation of arc-location always remains behind the first bulge, and thus, in the following, we refer to the first bulge as the "forearc bulge" (FB in Fig. 5). The location of the depression is relatively stable, being about $190 \mathrm{~km}$ from the trench for OP velocities lower than $5-6 \mathrm{~cm} / \mathrm{yr}$ (Fig. $5 \mathrm{~b})$. When entering the compressive regime $\left(v_{\text {op }} \geq\right.$ $6 \mathrm{~cm} / \mathrm{yr}$ ), its position shifts inland to about $260 \mathrm{~km}$ as a consequence of the growth of the forearc bulge. The bottom of the depression is always behind the lower-end estimation of arc-position and is hereafter referred to as the "arc depression" (AD in Fig. 5). The location of the second bulge $x_{A B}$ increases with OP velocity from $260 \mathrm{~km}$ at $v_{o p}=$ $2 \mathrm{~cm} / \mathrm{yr}$ to $410 \mathrm{~km}$ at $v_{o p}=8 \mathrm{~cm} / \mathrm{yr}$. The second bulge forms near the upper-end estimation of arc-position (Fig. $5 \mathrm{~g}$ ) and is thus thereafter referred to as the "arc bulge" (AB in Fig. 5).

The elevation of the forearc bulge $z_{F B}$ is approximately $0.3 \mathrm{~km}$ at $v_{o p}=2 \mathrm{~cm} / \mathrm{yr}$ and changes relatively little at $\mathrm{OP}$ velocities lower than $5 \mathrm{~cm} / \mathrm{yr}$. At higher $\mathrm{OP}$ velocities, that is when the OP is in compression, the forearc bulge rises with velocity, reaching $3.6 \mathrm{~km}$ at $v_{o p}=8 \mathrm{~cm} / \mathrm{yr}$ (Fig. $5 \mathrm{~d}$ ). In contrast, the arc-depression elevation $z_{A D}$ evolves approximately linearly from $\simeq-3 \mathrm{~km}$ to $\simeq-0.35 \mathrm{~km}$ when the $\mathrm{OP}$ is in extension (i.e, at $v_{o p}$ lower than $6 \mathrm{~cm} / \mathrm{yr}$ ) and is more stable under OP compression (Fig. $5 e$ ). The elevation of the second bulge $z_{A B}$ is positive regardless of the OP velocity (Fig. $5 f)$, with relatively low values $(0.15$ to $0.35 \mathrm{~km})$.

In what follows, the absolute difference between the minimum value of a location or an elevation and its maximum measured across the range of tested $v_{o p}$ is referred to as offset. Thus, in the models with reference rheological parameters, the offset of the steadystate location of the forearc bulge, arc depression and arc bulge are $50 \mathrm{~km}, 70 \mathrm{~km}$, and $150 \mathrm{~km}$, respectively. The offset of the steady-state elevation of the three topographic features are $3.3 \mathrm{~km}, 2.5 \mathrm{~km}$, and $0.2 \mathrm{~km}$, respectively.

\subsubsection{Models with a higher interplate friction:}


The models with an interplate friction coefficient $\mu$ of 0.04 are shown with light blue circles in Fig. 5. The increase of interplate friction from 0.01 to 0.04 only slightly diminishes slab dip at fixed $v_{o p}$ and thus has a negligible effect on the predicted arc region. The offsets in the steady-state locations of the forearc bulge in the high- $\mu$ models are similar to that in the reference models. As shown above, an increase in $\mu$ induces the downdip drag of the forearc region, and thus a higher $\mu$ mostly impacts the elevations while affecting little the locations. Particularly, the forearc bulge is deeper and the arc bulge is slightly higher. The most significant effect of an increase in $\mu$ is on the offsets of both the forearc bulge and the arc depression elevations which are about $30 \%$ higher than in the low- $\mu$ models. Moreover, the shift in the behavior of locations and elevations with $v_{o p}$ occurs at velocities around $5-6 \mathrm{~cm} / \mathrm{yr}$, similarly to the case with reference $\mu$, although the neutral $\mathrm{OP}$ tectonic regime is reached at $v_{o p} \simeq 2 \mathrm{~cm} / \mathrm{yr}$. This is, as explained in the previous section, because of the higher shear stresses which tend to pulldown the trenchward-most region of the OP. This effect becomes counterbalanced by the compressive stresses induced by interplate shear at $\mathrm{OP}$ velocities higher than the velocity inducing the far-field neutral regime (around $2 \mathrm{~cm} / \mathrm{yr}$ ). Note that additional models with a higher friction $(\mu=0.06$, Fig. S5a) have also been run for the analysis.

2.1.4.3 Models with a weaker overriding plate:

The models with a lower OP viscosity $\left(\eta_{o p}=3 \times 10^{23} \mathrm{~Pa} \mathrm{~s}\right)$ are shown by the orange circles in Fig. 5. The arc position shows little dependency on OP strength since , at fixed $v_{o p}$, changing $\eta_{o p}$ does not significantly affect slab dip (Fig S1).The low-OP viscosity models exhibit a forearc bulge that is farther from the trench $(50-100 \mathrm{~km})$. The $\mathrm{OP}$ viscosity impacts the offset of the forearc bulge location which is twice that in the models with reference $\eta_{o p}$. A weaker overriding plate offers less resistance to bending, causing a deeper forearc region at fixed values of $v_{o p}$ than in the models with reference $\eta_{o p}$, and a less prominent forearc bulge when the OP is in extension $\left(v_{o p}<4 \mathrm{~cm} / \mathrm{yr}\right)$. Interestingly, in the weak-OP models with a velocity of about $4 \mathrm{~cm} / \mathrm{yr}$, when the $\mathrm{OP}$ is in a neutral-tectonic regime, the forearc bulge vanishes. Further, the offset of elevation of forearc bulge and arc depression are clearly impacted by the strength of the OP, being about 50\% higher and 100\% lower, respectively than in the reference models. The shift in the behavior of locations and elevations of topographic features occurs at slightly lower $v_{o p}(\simeq 4 \mathrm{~cm} / \mathrm{yr})$ than at reference $\eta_{o p}$ because the neutral tectonic regime also occurs at a lower value of OP motion. Additional models with a higher OP viscosity $\left(\eta_{o p}=\right.$ $3 \times 10^{24} \mathrm{~Pa}$ s, Fig. S5b) confirm that the OP velocity at which the shift occurs tends to increase when increasing the $\mathrm{OP}$ viscosity.

2.1.4.4 Models with a weaker subducting plate:

The results of models with a lower SP viscosity $\left(\eta_{s p}=3 \times 10^{23} \mathrm{~Pa} \mathrm{~s}\right)$ are displayed with brown circles in Fig. 5. A weaker subducting plate undergoes higher bending at trench and thus exhibits a steeper geometry in the upper mantle (see Fig. S1a in Supp. Information), inducing predicted arc locations closer to the trench as well as a narrower arc region. The elevation of the forearc bulge is higher in the weak-SP models. This is because of the steeper geometry of the slab which may induce an enhanced horizontal trenchnormal interplate force and may limit the pull-down of the forearc region of the overriding plate. The main effect of lowering the SP viscosity is on the offsets of the forearc bulge location and elevation. They are only about half of those obtained with the reference $\mathrm{OP}$ viscosity. A shift in the behavior of the steady-state location and elevations with $v_{o p}$, cannot be clearly identified in those models with a weak SP. Yet additional models with a higher $\eta_{s p}$ of $3 \times 10^{24} \mathrm{~Pa} \mathrm{~s}$ (Fig. S5c in Supp. Info) indicate that the OP velocity at which the shift occurs (i. e. the velocity above which the forearc bulge substantially grows) increases with decreasing OP viscosity. 


\subsubsection{Summary of results from the first set of models at constant OP velocity}

Overall, several remarks useful for the second part of the study can be made about the modeled quasi-steady state topographic features at a constant OP velocity:

- The combination of the rheological parameters (which controls kinematics in the free models) and the OP velocity define the OP tectonic regime in the SP-free models. Thus, the different combinations explored in our models allows for encompassing a wide range of $\mathrm{OP}$ tectonic regimes.

- The first bulge forms in the idealized forearc region (i. e., between the trench and the geometrically-estimated arc region). The location of the depression and that of the second bulge, roughly bracket the estimated arc location. As shown by Shemenda (1993) and Hassani et al. (1997), the non-lithostatic tension at the subduction interface induces a vertical displacement of the overlying region of the overriding plate, and a depression is predicted to form above the deepest coupling point between the plates. Since the deepest coupling point between the overriding and subducting plates are at about a 70-km depth in our models (given the initial OP thickness), the lower estimation of the arc position roughly lie near the surface depression trough.

- A relatively high friction $(\mu=0.04)$ along the subduction interface results in a strong pull-down of the trenchward-most region of the OP and enhances compressive stresses within its distal regions. Therefore, an OP topographic profile with a deep arc depression may either reflect far-field extension and a weak interplate friction or far-field compression and a high interface friction.

- At constant rheological parameters, the offset in the steady-state locations of the forearc bulge and arc depression predicted are lower than $80 \mathrm{~km}$ for OP velocities in the range $2-8 \mathrm{~cm} / \mathrm{yr}$. The highest offset in the arc-bulge steady state location is up to $150 \mathrm{~km}$, except in the weak-OP models where it is up to $220 \mathrm{~km}$.

- At constant rheological parameters, the offsets in steady-state elevation of the forearc bulge and arc depression lie in the range $2-4 \mathrm{~km}$ across the range of $v_{o p}$ tested. The highest offsets of the forearc-bulge elevation are obtained in models with a high interplate friction or a weaker OP, and the lowest in models with a weak SP. The highest offsets of arc-depression elevation are observed with the high-friction models while the lowest are obtained with weak-OP models. The offsets of arcbulge elevation are up to $0.2 \mathrm{~km}$ for all choices of rheological parameters.

\subsection{Topographic evolution after a change in OP velocity}

\subsubsection{Topography following an OP-velocity increase}

We run two models in which the initial overriding plate velocity is the reference velocity $\left(v_{o p}=4 \mathrm{~cm} / \mathrm{yr}\right)$ and interplate friction of either 0.01 or 0.04 . The velocity is instantaneously increased to $6 \mathrm{~cm} / \mathrm{yr}$ at $t_{v a r}=54 \mathrm{Myr}$, that is during the quasi-steady state phase.

Figure 6a shows the OP surface elevation (color map) and estimated arc position (gray dots) with time in the model with relatively low interplate friction. After the slabsinking phase and the stabilization phase (from $t=11 \mathrm{Myr}$ to $t=14 \mathrm{Myr}$ ), the system tends towards a quasi-steady state. The topography during this phase, and prior to the increase in overriding plate velocity, is identical to that described above for the reference model (see Fig. 3). At $t=t_{v a r}$, the motion of the overriding plate suddenly increases. The increase in velocity lowers the slab dip and the arc region is slightly pushed inland by $20-30 \mathrm{~km}$. The acceleration generates strong vertical motions at the surface. On one hand, from the trench to approximately the location of the forearc bulge, i.e. from 0 to around $100 \mathrm{~km}$ from the trench, the surface undergoes subsidence just after the change 
in boundary conditions (see also Fig. S2 in Supp. Info.). A broader region, i.e. from $\simeq$ $100 \mathrm{~km}$ to $\simeq 500 \mathrm{~km}$ away from the trench, undergoes uplift on the other hand. This uplift creates an area of maximum elevation in the arc region at about 65 Myr. Then, we observe a reversal in the direction of vertical motions, although at smaller rates. Subsidence occurs in the arc/back-arc region, while the forearc region slowly uplifts, as described below. The surface elevation does not return to the quasi-steady state preceeding the kinematical changes before the end of the model time.

To describe in more details the time-evolution of topography, we track the evolution of three points at the surface of the OP (Figs. $6 \mathrm{~b}, \mathrm{c}, \mathrm{d}$ ): $\left.O F\right|_{t_{\text {var }}},\left.I F\right|_{t_{\text {var }}}$, and $\left.M A\right|_{t_{\text {var }}}$, that are the center of the outer forearc (dot-dashed lines), that of the inner forearc (dashed lines), and that of the arc (solid lines) at $t=t_{\text {var }}$, respectively (see sketch Fig. 6). These points are chosen because their locations on the slopes of the bulges at $t_{v a r}$ favor vertical motions as induced by the accommodation of the location of the topographic features to a new OP velocity. Our models also show that those points undergo the greatest vertical motions after a change in $\mathrm{OP}$ velocity. We monitor the vertical displacement $Z$ after $t_{v a r}$ and the rate of elevation change $\dot{z}$ of the three points. We moreover compute their maximum vertical displacement $H$ and maximum rate of elevation change $\dot{H}$ through time, hereafter also referred to as peaks, in the case of an uplift following a kinematic change. In the case of a subsidence, we compute their minimum.

Figure $6 \mathrm{~b}$ shows the vertical displacement of the tracked points with time. As described above, after the kinematic change, the point $\left.O F\right|_{t_{v a r}}$, which is the closest point to the trench, subsides while the points $\left.I F\right|_{t_{v a r}}$ and $\left.M A\right|_{t_{v a r}}$ uplift. Next, the point $\left.I F\right|_{t_{v a r}}$ first continues to uplift while the motion of points $\left.M A\right|_{t_{v a r}}$ and $\left.O F\right|_{t_{v a r}}$ slow-down and then slightly revert. Figure $6 \mathrm{c}$ shows that two main stages can be distinguished from the evolution of the rates of elevation change. A first stage that takes place between the change in $v_{o p}$ at $54 \mathrm{Myr}$ and $\sim 62 \mathrm{Myr}$ corresponds to the time interval during which absolute vertical motions are relatively high (Fig. 6c). The peak rate of elevation change $\dot{H}$ of points $\left.O F\right|_{t_{\text {var }}},\left.I F\right|_{t_{\text {var }}}$ and $\left.M A\right|_{t_{\text {var }}}$, which are reached during this stage, are $0.02 \mathrm{~mm} / \mathrm{yr}$ (at $58 \mathrm{Myr}$ ), $0.07 \mathrm{~mm} / \mathrm{yr}$ (at $62 \mathrm{Myr}$ ), and $0.36 \mathrm{~mm} / \mathrm{yr}$ (at $57 \mathrm{Myr}$ ), respectively. During a second stage, i.e. for $t \gtrsim 62 \mathrm{Myr}$, the rates of elevation change are much lower and slowly tend to zero, which corresponds to a progressive accommodation of the topography to a new steady-state set by the new overriding plate velocity. Unlike the rates of elevation change, the peak displacements are reached during the second stage for the three reference points $\left(H_{O F}=-0.5 \mathrm{~km}, H_{I F}=1.0 \mathrm{~km}\right.$ and $H_{M A}=1.2 \mathrm{~km}$, reached at 63 , 78 , and $67 \mathrm{Myr}$, respectively)

The evolution of topography (Fig. 6d) in the model where $v_{o p}$ increases from 4 to $6 \mathrm{~cm} / \mathrm{yr}$ but in which the interplate friction is set to 0.04 follows the same trends as above. In particular, the two stages in the evolution of the rates of elevation change of the three characteristic points can be observed on Fig. 6e. The first stage occurs between $54 \mathrm{Myr}$ and about $62 \mathrm{Myr}$, the second after $62 \mathrm{Myr}$. The peak rates of elevation change are close to that obtained at the reference $\mu$ with the exception of $\dot{H}_{M A}$ which is equal to $0.23 \mathrm{~mm} / \mathrm{yr}$ and is thus about a third of its value at reference $\mu$ (see Fig. 6f). Although these peaks are lowered in the case of $\mu=0.04$, the amplitudes of displacements are similar or higher than that at a lower $\mu$ (Fig. 6e) because they are reached later after the kinematic change than in the model at reference $\mu$ : at $68 \mathrm{Myr}, 90 \mathrm{Myr}$ and $66 \mathrm{Myr}$ for points $\left.O F\right|_{t_{\text {var }}},\left.I F\right|_{t_{\text {var }}}$ and $\left.M A\right|_{t_{v a r}}$, respectively.

Overall, these two models show that there are two modes of vertical motion that follow an OP-velocity increase. A first mode corresponds to a tilt of the overriding plate affecting the regions undergoing flexural bending. The tilt leads to a relatively rapid subsidence of the outer forearc and to a relative rapid uplift of the inner forearc and arc regions. This transient first stage lasts for about $8 \mathrm{Myr}$. It generates the maximum rates of elevation decrease in the outer forearc region and the maximum rates of elevation increase in the arc region. We interpret the tilt as being the surface expression of what Cerpa 
et al. (2018) referred to as a "tectonic pulse" after an OP-velocity change. Indeed, their models show that just after a kinematic change, the slab dip varies to accommodate the new boundary conditions (i.e. the new force balance) over some finite time. They observed that a peak in the far-field horizontal stresses (tectonic pulse) corresponded to the maximum rate of slab dip variation and argued that the kinematically-induced flattening or steepening of the slab was responsible for providing a temporary additional force at the subduction interface. The second mode of uplift that we observe corresponds to the steady-state accommodation of locations of bulges and depression to a new OP velocity(likewise the accommodation of slab dip observed by Guillaume et al. (2018); Cerpa et al. (2018), and is the main driver for the vertical displacement of the inner forearc region. A higher $v_{o p}$ is predicted to push steady-state topographic features farther from the trench (see Fig. 5). Thus, the point $\left.I F\right|_{t_{v a r}}$, which is on the arc-wards slope of the forearc bulge before the kinematic change, will be found closer to the top of this bulge well after the kinematic change. Also, the steady-state elevations of the forearc bulge and arc depression are predicted to vary by about $1 \mathrm{~km}$ when varying $v_{o p}$ from 2 to $4 \mathrm{~cm} / \mathrm{yr}$ (see Fig. 2.1.4), explaining thus the magnitude of the peak displacement measured around these regions. Finally, this steady-state accommodation is relatively slow, and thus the peak displacement $H_{I F}$ occurs a few dozens of Myr after $t_{v a r}$.

\subsubsection{Topography following a OP-velocity decrease}

We now investigate two models in which the OP velocity is instantaneously lowered from $4 \mathrm{~cm} / \mathrm{yr}$ to $2 \mathrm{~cm} / \mathrm{yr}$ at $t_{\text {var }}=54 \mathrm{Myr}$. We consider two values of interplate friction.

Figure 7 a shows the results of the model with $\mu=0.01$. Prior to the velocity change, the surface elevation is identical to that in the model with same interplate friction described above. The decrease in OP velocity steepens the slab and thus the arc region shifts trench-wards by about $30 \mathrm{~km}$. In addition, the velocity decrease induces a reversal tilt which causes the uplift of the region close to the trench and the subsidence of the arc and proximal back-arc regions. Fig. 7b displays the evolution of the vertical displacements of the three characteristic points. They undergo a reversal tilt just after the kinematic change and then slower opposite motions. The peak displacements $H_{O F}, H_{I F}$ and $H_{M A}$ are $0.8,-1.2$ and $-0.9 \mathrm{~km}$, respectively. The two main stages defined above are also observed here. The first stage $(54 \leq t \leq 61 \mathrm{Myr})$ exhibits high absolute rates of elevation change, as in the case of an OP-velocity increase (Fig. 7c). The peak rates are observed at $t \sim 56 \mathrm{Myr}$ for $\left.O F\right|_{t_{v a r}}\left(\dot{H}_{O F}=0.08 \mathrm{~mm} / \mathrm{yr}\right)$ and $\left.M A\right|_{t_{v a r}}\left(\dot{H}_{M A}=-0.34 \mathrm{~mm} / \mathrm{yr}\right)$ and at $t \sim 61 \mathrm{Myr}$ for $\left.I F\right|_{t_{\text {var }}}\left(\dot{H}_{I F}=-0.07 \mathrm{~mm} / \mathrm{yr}\right)$. The second stage $(t>61 \mathrm{Myr})$ corresponds to the stabilization of the vertical motions at rates progressively decreased.

The evolution of surface elevation in the model with $\mu=0.04$ is similar to that in the low-friction coefficient equivalent model. The rates of elevation change, displayed in Fig. 7f, show little differences with those measured in the model with a lower $\mu$. The peak rates $\dot{H}_{O F}=0.08 \mathrm{~mm} / \mathrm{yr}, \dot{H}_{I F}=-0.06 \mathrm{~mm} / \mathrm{yr}$ and $\dot{H}_{M A}=-0.37 \mathrm{~mm} / \mathrm{yr}$ are obtained at $57 \mathrm{Myr}, 65 \mathrm{Myr}$, and at $56 \mathrm{Myr}$, respectively. The noticeable difference observed between models with different interplate friction coefficients arises from the duration of the first stage following the kinematic change, which is slightly longer and ends at $t \sim 65 \mathrm{Myr}$ in the model with $\mu=0.04$.

The models with an OP-velocity decrease also exhibit two modes of vertical motions following a kinematic change. This is similar to the case with an OP acceleration with the exception that the motions have opposite directions. The first mode corresponds to a reverse tilt of the OP surface which induces uplift of the outer forearc region while the inner forearc and arc/back-arc regions subside. The second mode correspond to a steady-state accommodation of the flexural topographic features to the new boundary conditions. 


\subsubsection{Sensitivity of kinematically-induced vertical motions to model pa- rameters}

We now evaluate the sensitivity of the kinematics-induced changes in OP topography to the value of the change in OP velocity $\left(\Delta v_{o p}\right)$ and to the rheological parameters $\left(\mu, \eta_{o} p, \eta_{s p}\right)$. We quantify the sensitivity by calculating the peak displacement $H$ and the peak rate of elevation change $\dot{H}$ of the three points $\left.O F\right|_{t_{v a r}},\left.I F\right|_{t_{v a r}}$, and $\left.M A\right|_{t_{v a r}}$. The initial velocities encompass the range 2 to $8 \mathrm{~cm} / \mathrm{yr}$ and the interval of absolute OPvelocity changes spans the range -6 to $+6 \mathrm{~cm} / \mathrm{yr}$ and (see Table $\mathrm{S} 1$ in Supp. Info). This range of absolute velocity changes have been found consistent with first-order estimations of changes in OP-kinematics in natural subduction zones in the last 20 Myr by Cerpa et al. (2018).

Our 46 experiments (33 shown here and 13 displayed in Fig. S5 in Supp. Info) show that the peak displacement of point $\left.O F\right|_{t_{v a r}}$ in the outer forearc region $\left(H_{O F}\right.$, Fig. 8a), that of point $\left.I F\right|_{t_{v a r}}$ in the inner forearc region $\left(H_{I F}\right.$, Fig. $\left.8 \mathrm{~b}\right)$, and that of point $\left.M A\right|_{t_{v a r}}$ in the arc region $\left(H_{M A}\right.$, Fig. $\left.8 \mathrm{c}\right)$ evolve approximately linearly with the value of $\Delta v_{o p}$ regardless of the rheological parameters, as shown by the good linear-fit of modeled values (regression coefficient $R^{2} \geq 0.79$, Fig. 8). Thus, in what follows, we present our results in terms of the fitting curves. Note that while the peak elevation of the outer forearc region decreases with $\Delta v_{o p}$, that of the inner forearc and the arc regions increases with $\Delta v_{o p}$. The same trends are observed for the peak rates of elevation change of points $\left.O F\right|_{t_{\text {var }}}\left(\dot{H}_{O F}\right.$, Fig. 8d), IF $\left.\right|_{t_{\text {var }}}\left(\dot{H}_{I F}\right.$, Fig. 8e), and $\left.M A\right|_{t_{\text {var }}}\left(\dot{H}_{M A}\right.$, Fig. 8f $)$.

The values of $H_{O F}$ predicted in models with reference rheological parameters (darkblue line) are between 2 and $-2 \mathrm{~km}$ for velocity changes between $-6 \mathrm{~cm} / \mathrm{yr}$ and $+6 \mathrm{~cm} / \mathrm{yr}$. The peak displacements of the outer forearc are generally reached at the beginning of the second stage following the kinematic change (see Fig. S4a), as they are induced by the addition of a first transient strong vertical motion and a steady-state accommodation to new boundary conditions (see Section 2.1.4). The models show a relatively weak dependence of $H_{O F}$ on the interplate friction coefficient (light blue line) but a stronger influence of plates viscosity decrease (orange and brown lines). The higher impact of OP and SP strengths on $H_{O F}$ may be due to the higher effect of these parameters on the steady-state location and elevation of topographic features.

The peak displacements $H_{I F}$ are generally reached long after the kinematic change $(t>22 \mathrm{Myr}$, see Fig. S4b) because this region is mostly sensitive to the slow steadystate accommodation to new boundary conditions. For the models with reference rheological parameters, $H_{I F}$ predictions are between $-5 \mathrm{~km}$ and $4 \mathrm{~km}$ for velocity changes within the range -6 to $6 \mathrm{~cm} / \mathrm{yr}$. Only a weaker subducting plate has a significant effect on the topographic response of the inner forearc to a change in OP velocity. This may be mainly due to the relatively low sensitivity of the steady-state elevation of the forearc bulge to $v_{o p}$ in weak-SP models (see Fig. $5 \mathrm{~d}$ ).

The peak displacements $H_{M A}$ are observed between the first and the beginning of the second stage following the kinematic change (see Fig. S4c) since the magnitude of displacements during the steady-state accommodation in this region is negligible. The models with reference rheological parameters, display values of $H_{M A}$ between $-2.5 \mathrm{~km}$ and $3 \mathrm{~km}$ for velocity changes within the range -6 to $6 \mathrm{~cm} / \mathrm{yr}$. The peak displacement of the arc appears most sensitive to the value of the interplate friction, which may be explained by the slightly higher offset of steady-state elevations of the arc depression with changing $v_{o p}$.

Our predictions of peak rates $\dot{H}_{O F}$ in models with reference rheological parameters encompass the range 0.6 to $-0.7 \mathrm{~mm} / \mathrm{yr}$ for absolute velocity changes of less than $6 \mathrm{~cm} / \mathrm{yr}$. These peak rates are reached within the first 15 Myrs after the kinematic change (see e.g. Fig. S4d). A higher interplate friction coefficient, a weaker overriding plate, or 
a weaker subducting plate, all produce peak rates of elevation change in the outer forearc $\dot{H}_{O F}$ that are lower than those predicted with reference rheological parameters. The SP viscosity and the interplate friction have the highest control on $\dot{H}_{O F}$, since the values of $\dot{H}_{O F}$ are only about $50 \%$ and $60 \%$, respectively of that obtained with the reference viscosity. The $\mathrm{OP}$ viscosity has a more modest effect.

The peak rates $\dot{H}_{I F}$ in models with reference rheological parameters lie in the range -0.5 to $0.3 \mathrm{~mm} / \mathrm{yr}$ for absolute values of $\Delta v_{o p}$ lower than $6 \mathrm{~cm} / \mathrm{yr}$. Thus, the topographic response of the inner forearc is lower than that of the outer forearc region. The interplate friction coefficient has not a significant influence on $\dot{H}_{I F}$. The highest effect appears to be that of the SP viscosity which produces values of $\dot{H}_{I F} 50 \%$ lower than the values at reference $\mathrm{SP}$ viscosity. A weak overriding plate tend to moderately increase the topographic response of the inner forearc.

At reference rheological parameters, the absolute values of the peak rates $\dot{H}_{M A}$ range between -0.9 and $0.7 \mathrm{~mm} / \mathrm{yr}$ for the tested values of absolute $\Delta v_{o p}$, and are reached during the first 15 Myrs after the kinematic change. The sensitivity of the peaks to $\Delta v_{o p}$ in the mid-arc is the strongest in the three regions. As for the peak rate of the outer forearc, the SP viscosity has the strongest effect on the peak rate of elevation change in the arc with values of about $50 \%$ of that at reference $\eta_{s p}$. A weak overriding plate slightly enhances the topographic response of the arc. A higher friction coefficient marginally decreases the amplitude of the elevation velocity. The dependence of $\dot{H}_{M A}$ on the rheological parameters is further confirmed by additional tests shown in Fig. S5.

\subsubsection{Summary of results from the models with a variable OP velocity}

We can draw several remarks from the models with a variable OP velocity:

- A velocity change generates a transient tilt of the regions of the overriding plate that undergo flexural bending. The tilt occurs around a rotation point that is situated nearby the forearc bulge crest, and that we have defined as the limit between the outer and the inner forearc.

- After a velocity increase, the outer forearc region undergoes a rapid subsidence while from the inner forearc to the back-arc, a rapid uplift occurs. The first overshoot is followed by a reversal of motions, yet at a slower rate. The outer-forearc uplifts while the inner-forearc and arc/back-arc subside. The system tends towards a quasi-steady state after a few dozen of Myrs.

- Compared to the case of an OP-velocity increase, the vertical motions are reversed in the case of a a OP-velocity decrease.

- The peak rates of elevation change are reached during the first transient episode of tilt regardless of the value of the initial $v_{o p}, \Delta v_{o p}$ and the rheological parameters. Given the timescales (10 Myrs), the tilting response is unlikely to be dominated by the elastic response.

- In models with reference rheological parameters, the absolute values of the peak rates of elevation changes of the outer forearc and of the arc regions encompass the range 0.1 to $0.6 \mathrm{~mm} / \mathrm{yr}$ for absolute velocity changes between 1 and $6 \mathrm{~cm} / \mathrm{yr}$. The peak rates are lower in the inner forearc region (about $50 \%$ lower).

- We predict that SP viscosity has the strongest effect on the topographic response from the outer forearc to the proximal back-arc. The effect of the OP viscosity is moderate and that of the interplate friction coefficient is the weakest. 


\section{Discussion}

\subsection{OP topography at constant $v_{o p}$ : Comparison with previous stud- ies}

The modeling studies that have analyzed the subduction-induced OP topography have principally focused on the first stage of slab sinking through the upper mantle (Zhong \& Gurnis, 1992; Hassani et al., 1997; Hampel \& Pfiffner, 2006; Bonnardot et al., 2008; Crameri et al., 2017). In contrast, our study focuses on the stage of quasi-steady state after slab anchoring at the base of the upper mantle. Despite these differences, we can discuss our findings in light of several previous studies.

Our modeling approach is similar to that of Bonnardot et al. (2008), and thus our models are in good agreement with theirs. These authors analyzed the OP topography in the case of a fixed overriding plate, assuming elastic plates and an isoviscous mantle. They showed that the bending of an elastic overriding plate induced by the interplate coupling was characterized by the presence of a prominent bulge next to the trench followed landwards by a relatively deep depression. Their modeled bulges and depressions are comparable in terms of amplitude and position relative to the trench to our first bulge and depression in our models with higher plates viscosity. One notable difference between our models and that of Bonnardot et al. (2008) is that we observe the development of a smaller second bulge after (landwards) the depression, both during the slab-sinking phase and during the quasi-steady state phase (see Fig. 3). The lack of a second bulge in the models of Bonnardot et al. (2008) might be due the relative short overriding plate $(\sim$ $500 \mathrm{~km}$ ) that they used.

Hampel and Pfiffner (2006) assessed the influence of the OP trenchward motion and of the plate interplate coupling on OP topography during the slab sinking phase. As our models, theirs showed the presence of a high bulge at the surface of the overriding plate at less than $200 \mathrm{~km}$ from the trench. Hampel and Pfiffner (2006) discussed the role of the OP motion and the friction at the subduction interface on the location and height of this bulge, and concluded on the primary role of friction in controlling OP topography. Our parametric study further demonstrates that the topographic flexural bulges are controlled by both the OP tectonic regime (affected by the kinematic parameters) and the rheological parameters, in a non-monotonic manner.

Since the values of relaxation times are relatively low, our models can be compared to the topography that develop in models without elasticity (e.g., Zhong \& Gurnis, 1992). For instance, Crameri et al. (2017) carried out a detailed parametric study to evaluate the influence of a range of physical and geometric parameters on topography in free-subduction models with viscoplastic plates (temperature-dependent viscosity). Their models, limited to the slab-sinking phase, consistently show the development of a bulge and a relatively large and deep depression. Unlike other studies, Crameri et al. (2017) suggested that the bulge corresponds to the island arc and the depression to a back-arc depression. Although no details are given by the authors on the horizontal distance between the trench and the bulge that their models produce, we can roughly estimated it to be about $100 \mathrm{~km}$. Such a distance is consistent with the location of what we have referred to as the forearc bulge. Accordingly the arc-trench distances in present-day subduction zones lie mostly within the range 150-300 km (e.g., Syracuse \& Abers, 2006). Other profound differences exist between the results reported by Crameri et al. (2017) and ours, which may be caused by the different assumptions on rheology. They might also highlight the effect of the OP velocity. These differences are discussed below.

Crameri et al. (2017) concluded that both buoyancy and slab dip were the main controls on the amplitude and location of modeled topographic features. On one hand, the major role of OP buoyancy on topography has also been previously demonstrated in models more similar to ours (e. g. (visco)elastic plates, a Newtonian upper-mantle) 
(Hassani et al., 1997; Buiter et al., 2001). On the other hand, our modeling results show that the relationship between slab dip and OP topography is less straightforward than suggested by Crameri et al. (2017). The latter authors proposed that slab dip exerts a positive effect on trench depth and a negative effect on the amplitude of OP bulge and depressions. In other words, in their models, the steeper the slab, the deeper the trench and the flatter the overriding plate. In our models with a constant $v_{o p}$, we observe that the trench depth rather increases with OP velocity and thus decreases with slab dip (see Fig. S1; see also Cerpa et al. (2018) for discussion on the correlation between slab dip and $v_{o p}$ in models). A higher velocity induces higher interplate shear stresses along the subduction interface, favoring OP bending and dragging down the trench. A weaker subducting plate reduces the stresses transmitted along the slab axes towards the plates interface, inducing thus a shallower trench.

Also, the relationship between slab dip and the amplitude of bulges and depressions is less obvious in our models than proposed by Crameri et al. (2017). In our models slab dip and OP velocity are anti-correlated at steady-state. In contrast, the steadystate amplitude of the depression and bulges does not follow a monotonic trend with OP velocity because of their dependence on the OP tectonic regime and on the friction at the plates interface.

Moreover, in the models of Crameri et al. (2017), the (back-arc) depression is a longwavelength feature that has an horizontal extent of 1000 to $2000 \mathrm{~km}$. In our models, the depression is an intermediate-wavelength feature of width $\sim 100-150-\mathrm{km}$, although it reaches a width of $200-250-\mathrm{km}$ during the sinking phase. The wider depression obtained by Crameri et al. (2017) may be due to the higher viscosity of the overriding plate which raises up to $10^{26} \mathrm{~Pa} \mathrm{~s}$ in the uppermost lithosphere. Riel et al. (2017) reported the OP topography during slab stagnation at the base of the upper mantle, similarly to us. They, however, used a thermo-mechanical model with a temperature-dependent viscosity and considered only the case of two free plates. The authors also showed the development of a bulge and a depression at the OP surface, although they interpreted these as solely driven by the viscous stresses beneath the plate. Notably, in their models, the OP viscosity exhibits values that are lower than that in Crameri et al. (2017). This may explain why the topographic depression in the models of Riel et al. (2017) has a wavelength closer to our predictions.

\subsection{Topography following a change in OP velocity}

Because the location and elevation of the topographic features induced by OP bending are affected by kinematics, our results show that sudden changes in boundary conditions lead to important changes in OP surface elevation. The models predict two modes of vertical motions following a kinematic change.

The first mode occurs just after the kinematic change and is transitory, similarly to the "tectonic pulse" defined by Cerpa et al. (2018). This mode corresponds to the tilting of the region of the overriding plate undergoing flexural bending. Important vertical displacements (of magnitude of one to a few $\mathrm{km}$ ) during this transient stage are observed, mainly in the vicinity of the arc-region. Most importantly, this first mode leads to high peaks of rate of elevation change in the outer forearc and in the arc region, both of which undergo opposite directions of motions. The absolute values of peak rates are roughly in the range $0.1-0.8 \mathrm{~mm} / \mathrm{yr}$ for absolute velocity changes between 1 and $6 \mathrm{~cm} / \mathrm{yr}$. The peak rates are the highest in the outer forearc and mid-arc regions.

We find that the SP strength has the highest (positive) impact on the topographic response. Thus, we can hypothesize that old-slab subductions may undergo higher variations in OP topography after a kinematic change than young-slab subductions. The effect of OP viscosity and interplate friction are found less significant. Nevertheless, in 3$\mathrm{d}$ settings, along-strike variations in $\mathrm{OP}$ and interplate strengths might cause an along- 
strike segmentation of the kinematically-induced topographic response of the overriding plate.

Our predictions of vertical motions just after a kinematic change may be overestimated because of the assumption of instantaneous changes. In Nature, plates absolute velocity changes may take place over some finite duration. For instance, the trenchward motion of the South-American plate may have started decreasing after around $20 \mathrm{Ma}$, and the deceleration may have hold for 10 to 15 Myr (Sdrolias \& Müller, 2006). We have thus tested the consequences of a progressive change in $v_{o p}$ on the associated OP surface vertical motion (Fig. S6 in the Supp. Info). Overall, we find that the time over which the kinematic changes occur affects the predicted motions. Yet, we find that changes occurring in less than about 10 Myr could have a detectable first-order impact (rates of the order $0.1 \mathrm{~mm} / \mathrm{yr}$ ) on the non-isostatic evolution of OP topography.

The second mode of vertical motion mainly affects the displacement of the inner forearc region. The absolute values of the peak displacements in this region are 1 to $4 \mathrm{~km}$ for velocity changes between 1 and $6 \mathrm{~cm} / \mathrm{yr}$. The rates of elevation change are nonetheless small $(<<0.1 \mathrm{~mm} / \mathrm{yr})$ in the second mode compared to those measured for the first mode.

\subsection{Comparison to natural cases}

Overriding plate topography in dynamic subduction models coherently shows the development of flexural topographic features. A direct comparison of bathymetry and hypsometry to modeled topography is yet limited because of other first order processes that can affect the surficial shape at the vicinity of convergent margins. In the forearc, the state of stresses and the type of the margin (accretionary vs. erosional), in conjunction with brittle deformation, affect surface topography near the trench (Noda, 2016). In the active arc, the thickening of the crust by magma emplacement as well as the erupted material are the main drivers for the shaping of the surface. In addition, tectonic forces induce crustal thickening/thinning and can also impact topography in the arc and the proximal regions. Despite these facts, geophysical observations have been used to shed light on the intermediate wavelength $(\simeq 100 \mathrm{~km})$ dynamically-induced topography (Davies, 1981; Billen \& Gurnis, 2005). It would be interesting to carry comparable studies that focus on the development of a forearc bulge and its relation to the kinematic far-field conditions, a relation that is one of our main observations. Concerning the topographic effects of a change in OP-velocity, it may be preferable to discuss the implications to natural cases in terms of the modeled rates of elevation changes.

Our models show that the first mode can induce vertical motions that are in the opposite direction to the steady-state motions when the slab is stagnating at the base of the upper mantle. As shown by Chen et al. (2017), slab flattening at the mantle transition zone provokes subsidence of the forearc region (from the trench up to the location of the OP depression in their models). We argue that, in the same context, an OP-velocity decrease could cause instead transient uplift of the forearc region. Long-term forearc uplift has been revealed in number of subduction zones from analysis of coastal shorelines (e.g Pedoja et al., 2011, and references therein) and is often attributed to the entrance of buoyant features into the subduction trench. Several natural examples of coastal uplift occur, however, in regions of "normal" oceanic lithosphere subduction, for instance along most of the western South American coast (Saillard et al., 2017; Pedoja et al., 2006) (with order of magnitude between $0.1-1.0 \mathrm{~mm} / \mathrm{yr}$ ). We argue that it is possible that the continuous slow-down of the absolute west-ward motion of the South-American continent in the last 10 to 20 Ma (Somoza \& Ghidella, 2012; Sdrolias \& Müller, 2006) above a stagnating Nazca plate (Fukao \& Obayashi, 2013) might also contribute to the upward displacement of the forearc. 
The vertical motions of the forearc in Northeast Japan have been summarized for the Neogene and Quaternary by Regalla et al. (2013). Their synthesis show two stages of opposite directions of forearc motions. From about 30 to $10 \mathrm{Ma}$, forearc subsidence independent of the sedimentary load is recorded along the northern-east Honshu forearc, and cannot be fully attributed to extensional faulting. From about $3 \mathrm{Ma}$, the same region has undergone uplift. This change in the direction of upward motion of the forearc coincides with a shift in the tectonic regime of the back-arc which has passed from being in extension during the lower Miocene into being in contraction since the upper Pliocene. The contemporaneous changes in these two distant regions lead Regalla et al. (2013) to propose that variations in the kinematics of convergence between the overriding plate and the subducting Pacific Plate was the driving mechanism. In addition, kinematic reconstruction models for the Japan subduction zone, estimate an increase in the trenchward motion of the overriding plate from about $30 \mathrm{Ma}$ until about $20 \mathrm{Ma}$, as a result of the Japan Sea opening (Sdrolias \& Müller, 2006). Our results would suggest that the NE-Japan forearc subsidence might have been triggered by the increase in OP velocity. The more recent forearc uplift might be the reversal of this motion or the result of a slight increase in the trench-normal overriding plate motion from $10 \mathrm{Ma}$.

To further test the mechanism for kinematically-induced overriding-plate surface motions that we derive from our models, we ideally would need to assess vertical motions around paleo-arc regions when changes in OP-velocity have occurred. Yet, in most cases we may lack such an information because of the many overlapping processes that affect the shaping of surface around active or paleo-arc fronts. The rear arc or the proximal back-arc might be a more suitable region for seeking indicators of vertical motions correlated with changes in kinematic boundary conditions. To our knowledge, only a few examples exist where vertical motions in the rear arc/back-arc region have been suggested to have been driven by subduction dynamics (e.g. the Western Mediterranean (Duggen et al., 2003), the Eastern Caribbean (Iturralde-Vinent \& MacPhee, 1999). Unfortunately, the timing of these events and the rate of the paleo-vertical movements are poorly constrained. Future research in this direction may help to decipher the potential contribution of the kinematically-induced vertical motions.

\subsection{Model limitations}

Our mechanical models consisting of Maxwell viscoelastic plates and restricted to the upper mantle may not capture all the complexity of the Earth. First, we consider only $70-\mathrm{km}$ thick plates of uniform strength, roughly corresponding to an average 40-Ma old subducting plate. Thereby, we do not consider the effect of an age-dependent subducting plate viscosity and thickness. In particular, we do not simulate the dynamicallyinduced OP topography either in a young and warm-slab or in a old and cold-slab subduction zone. Assuming that these end-members could be modeled using a very weak $\left(\eta_{s p}<<10^{24} \mathrm{~Pa} \mathrm{~s}\right)$ and a very strong $\left(\eta_{s p}>>10^{24} \mathrm{~Pa} \mathrm{~s}\right)$ subducting plate, respectively, our models with a variable $v_{o p}$ suggest that the amplitude of tilting would tend to decrease in the former case whereas the opposite would be expected in the latter case. Several studies suggested, however, that the viscosity of the plates may be low, in the order of $\sim 10^{22} \mathrm{~Pa} \mathrm{~s}$ (Wu et al., 2008), regardless of the age of the plate. Such a low SP strength may mitigate the tilting of OP surface after a change in boundary conditions. However, because of the opposite effect of the OP viscosity (Fig. 8), we argue that an equally lowered OP viscosity is likely to partly counter-balance the effect of a very weak SP. On the other hand, a reduced OP-to-mantle viscosity ratio $\left(\sim 10-10^{2}(\mathrm{Wu}\right.$ et al., 2008; Ribe, 2010; Loiselet et al., 2009) compared to the values that we considered here $\left(10^{3}-10^{4}\right)$ might have additional effects on OP topography. The viscous forces induced by mantle corner flow are indeed predicted to deflect the overlying OP but, in our models, the relatively high viscosity ratio may prevent the relatively low viscous suction from overcoming the bending resistance of the plate. Note that based on analog models with plate-to-mantle viscosity ratios of $\sim 10^{2}$, Chen et al. (2017) suggested that the 
effect of suction by corner flow is negligible compared to that induced by the traction at the subduction interface.

Our models only account for subduction within the upper mantle and slab-pull driven mantle flow, thereby neglecting the dynamic effect of a large-scale mantle convection cell induced e.g. by the penetration of the slab into the lower mantle, sometimes referred to as "slab suction" (Conrad \& Lithgow-Bertelloni, 2002; Faccenna et al., 2013). For instance, mantle dynamics has been invoked as such to explain an extra west-ward push of the South American plate towards the trench and to explain the compressive event that triggered the Andean orogeny (Husson et al., 2012; Faccenna et al., 2017). Nonetheless, our models with an imposed far-field OP velocity may be regarded as an attempt to account for the potential impact of the large-scale mantle dynamics which partly controls plate kinematics and prevents the motion of the overriding plate from being solely driven by slabpull (Becker \& O’Connell, 2001; Husson, 2012).

A recent study has shown that the different interaction modes between the subducting slab and the lower mantle induce a variety of patterns of long-wavelength $(\sim 1000$ s $\mathrm{kms}$ ) dynamic topography in regions of the OP far from the trench and thus not affected by the dynamically-induced flexural topography (Briaud et al., 2020). Overall, the authors show that the slab penetration into the lower mantle may induce surface vertical motions at rates in the order of $0.1 \mathrm{~mm} / \mathrm{yr}$. In principle, this is comparable to our predicted rates of elevation changes after kinematic variations. However, in contrast to the dynamic topography modeled by Briaud et al. (2020), our predicted mechanism acts at intermediate wavelengths $(100 \mathrm{~s} \mathrm{kms})$ and on regions distant by less than about $500 \mathrm{~km}$ from the trench. Deciphering the contributions of these two different mechanisms in the non-isostatic topography of natural subduction zones may be a potential topic of future studies.

\section{Conclusion}

We assess the dynamically-induced topography of the overriding plate at quasi-steady state when the subducting plate stagnates at the bottom of the upper mantle. Our models predict the formation of a bulge in the forearc, as well as a depression and a smallamplitude second bulge that may host the arc and part of the back-arc. The elevation and location of these flexural topographic features at steady-state vary with the rheological and kinematic parameters, following the OP tectonic regime and the amount of shear at the subduction interface. Their distance to the trench increases with $\mathrm{OP}$ velocity regardless of the rheological parameters. The sensitivity of their elevation to OP velocity is higher when interplate friction is high or SP viscosity is high.

We further show the topographic effects of a variation in OP velocity during slab stagnation. A transient tilt takes place after the kinematic change. It lasts between 5 and $15 \mathrm{Myr}$, depending on both the magnitude of the velocity change and the rheological parameters. In the case of an OP-velocity increase, this episode exhibits rapid subsidence of the outer forearc and rapid uplift of the arc/proximal back-arc regions (rates of elevation changes in the order of $0.1 \mathrm{~mm} / \mathrm{yr}$ ). The opposite occurs for an OP-velocity decrease. We find that the peak displacements and the peak rates of elevation changes behave approximately linearly with the value of change in OP velocity. Also, the SP strength may have the strongest impact on the topographic response of the OP during this stage. The tilt is followed by a reversal of the vertical motions, yet at a much slower rates, that accommodates the new OP velocity in a few dozens of Myrs following a kinematic change.

In conclusion, we propose a new mechanism of rapid topography evolution that may affect the overriding plate surface from the trench to up to $500 \mathrm{~km}$ inland, and may last for less than 15 Myr after a change in the velocity of the overriding plate. We suggest 
that such a mechanism may be a first-order process that should be accounted for when quantifying the intermediate-wavelength non-isostatic topography in subduction zones. 


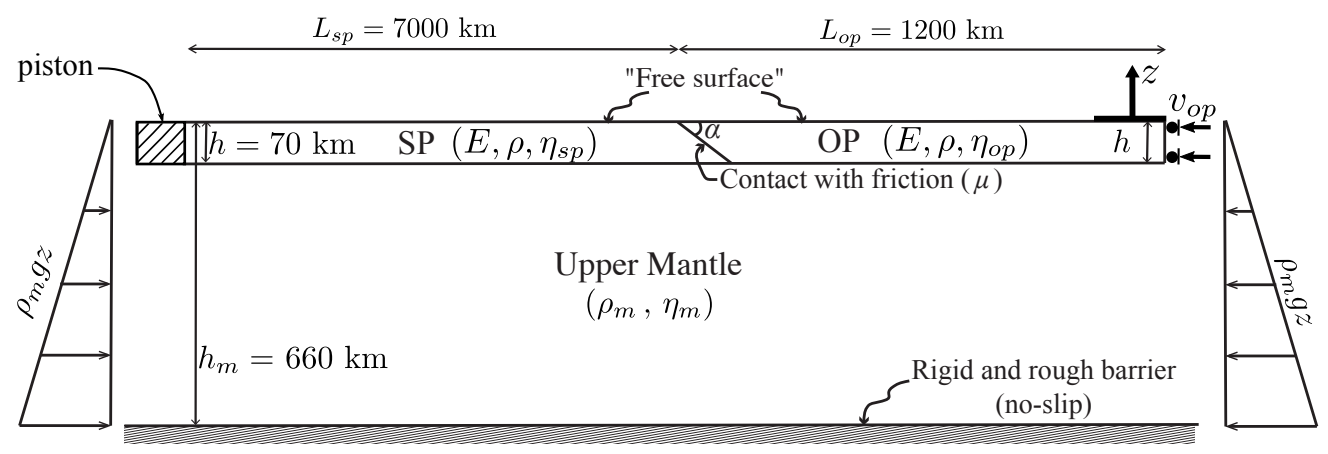

Figure 1. Sketch of models at $t=0$, mechanical parameters and boundary conditions. Rheological parameters are given Table 1. The initial dip of subduction interface $\alpha$ is $25^{\circ}$. Throughout this study, all velocities are expressed in the fixed reference frame attached to the base of the upper mantle, that is an immobile-lower mantle reference frame. The z-axis illustrates the reference vertical position used to calculate elevations, as defined in the main text. 

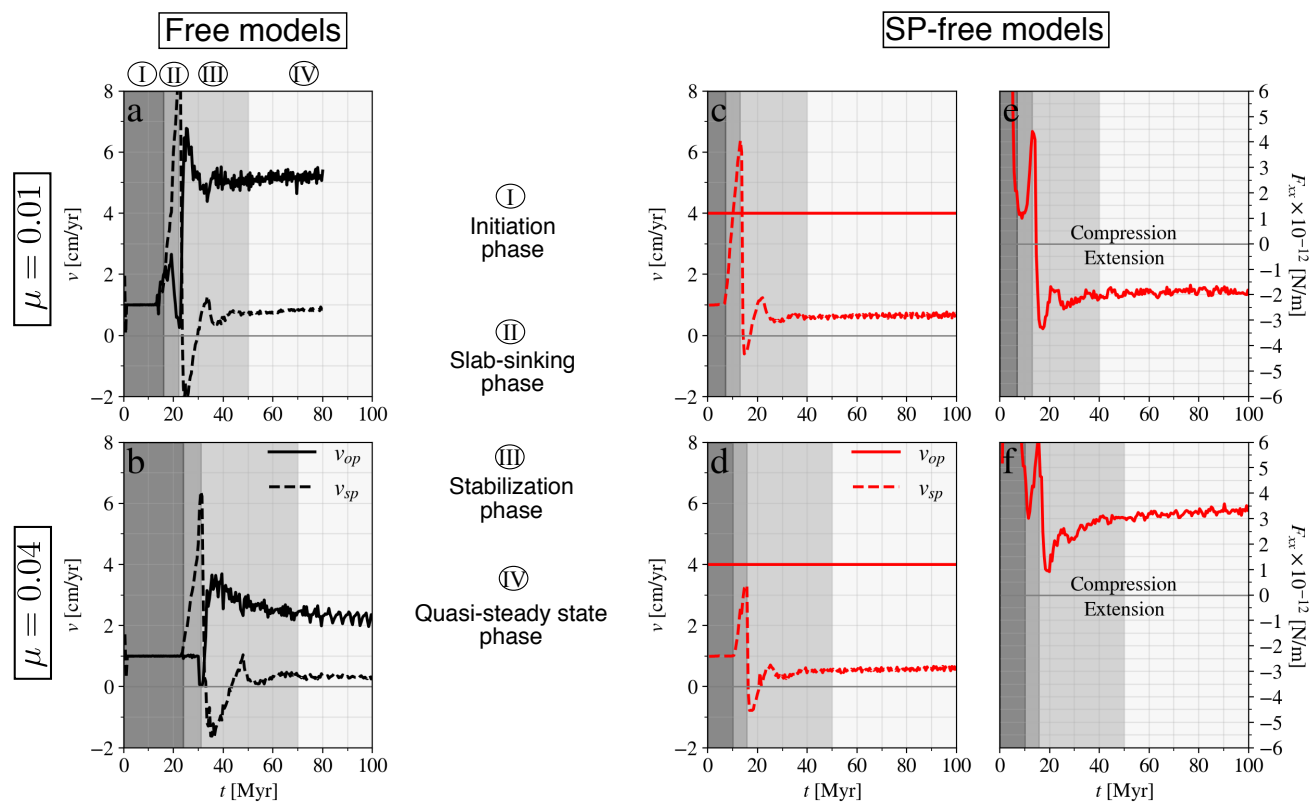

Figure 2. Kinematic evolution of free models $(\mathrm{a}, \mathrm{b})$ and SP-free models $(\mathrm{c}, \mathrm{d})$ with reference constant OP velocity, for an interplate friction coefficient of 0.01 (top row) and 0.04 (bottom row). The far-field horizontal force calculated at the trailing edge of the overriding plate (sse definition in the main text) is displayed for the SP-free models (e,f). 

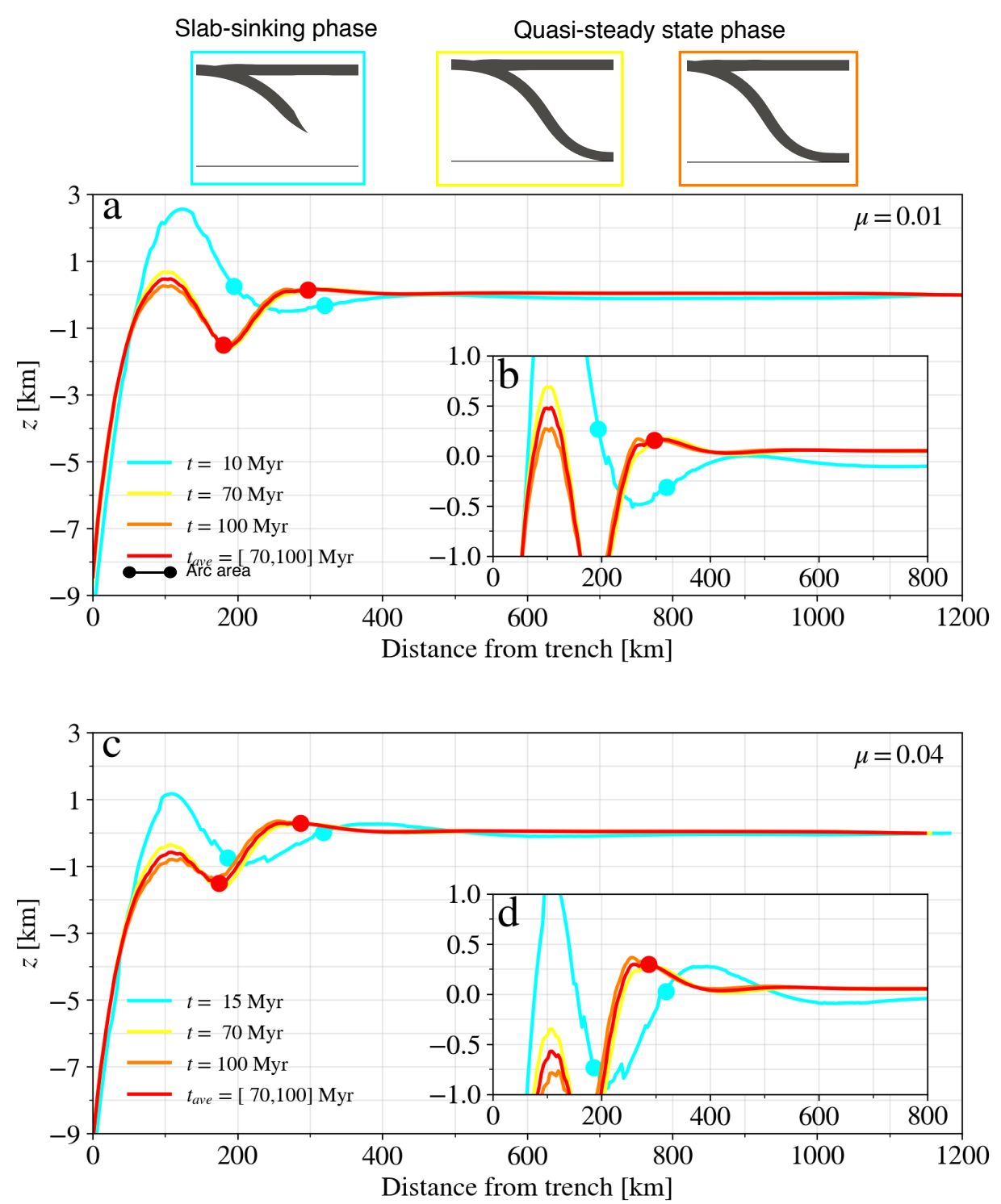

Figure 3. Topographic profiles during the slab sinking phase (cyan lines), and the quasisteady state phase (yellow and orange lines) for the models with the reference constant overriding plate velocity of $4 \mathrm{~cm} / \mathrm{yr}$ with reference rheological parameters (a,b) and that with $\mu=0.04$. Time-averaged profiles during the quasi-steady state in each model are also displayed (red lines). The circles represent the predicted arc location, as described in the text. Snapshots of the geometry of the system corresponding to each profile in the reference model are displayed in the small sub-panels above for illustration. 

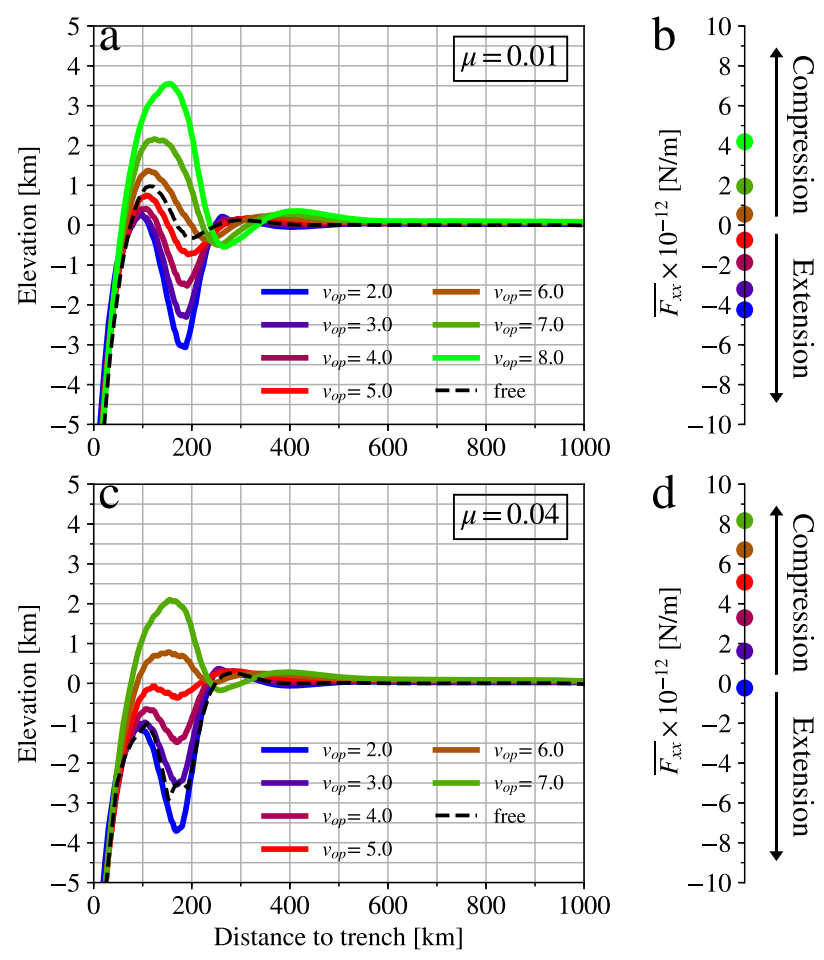

Figure 4. Left columns: Time-averaged topographic profiles for models with $\mu=0.01$ (a) and $\mu=0.04$ (c) and various constant $\mathrm{OP}$ velocities. The plate viscosities are set to their reference value $\left(10^{24} \mathrm{~Pa} \mathrm{~s}\right)$. For comparison, we have also plotted the profiles obtained in the free models with identical rheological parameters. Right columns: Time-averaged far-field horizontal force $F_{x x}$ within the overriding plate for the same models. $F_{x x}$ is the integral over the plate thickness of the non-lithostatic stress vector at the trailing edge of the overriding plate. Negative values represent extension and positive values compression. 


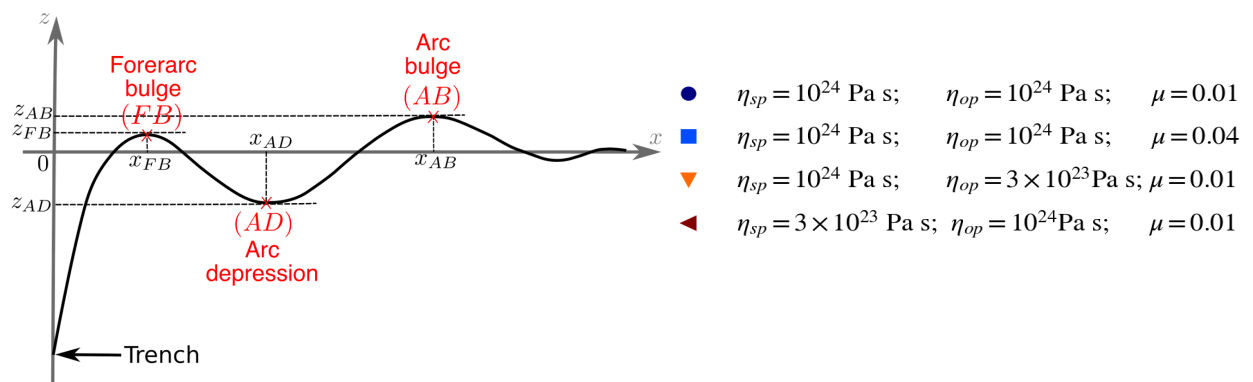

point $F B$
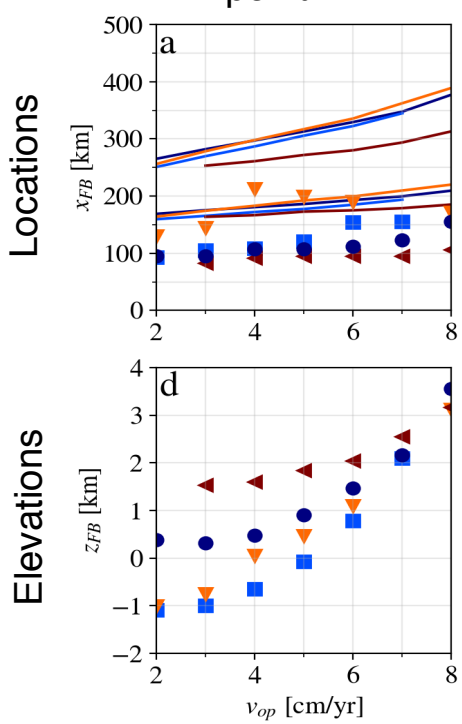

point $A D$
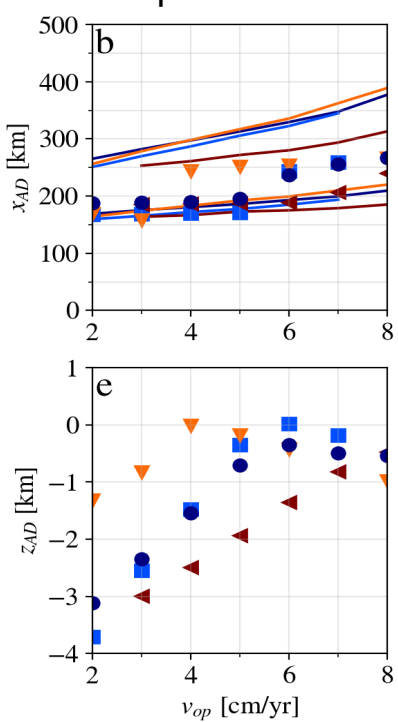

point $A B$
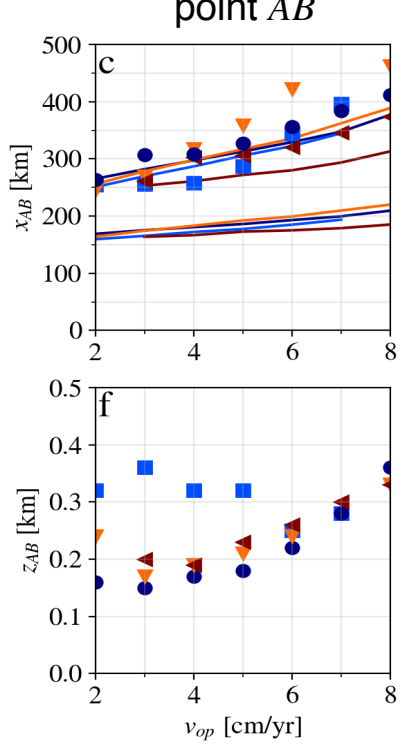

Figure 5. Diagram depicting the influence of model parameters on the steady-state position of the bulges and the depression as well as on that of the arc. The first (a,b,c) and the second rows (b,e,f) show the location and the elevation, respectively, of bulges and depressions, as defined in the overlying sketch. These values are displayed against overriding plate velocity. The solid lines on the first row indicates the idealized arc location. The different colors represent the different sets of parameters. The steady-state values are obtained by time-averaging over the last $20 \mathrm{Myr}$ of each model. 

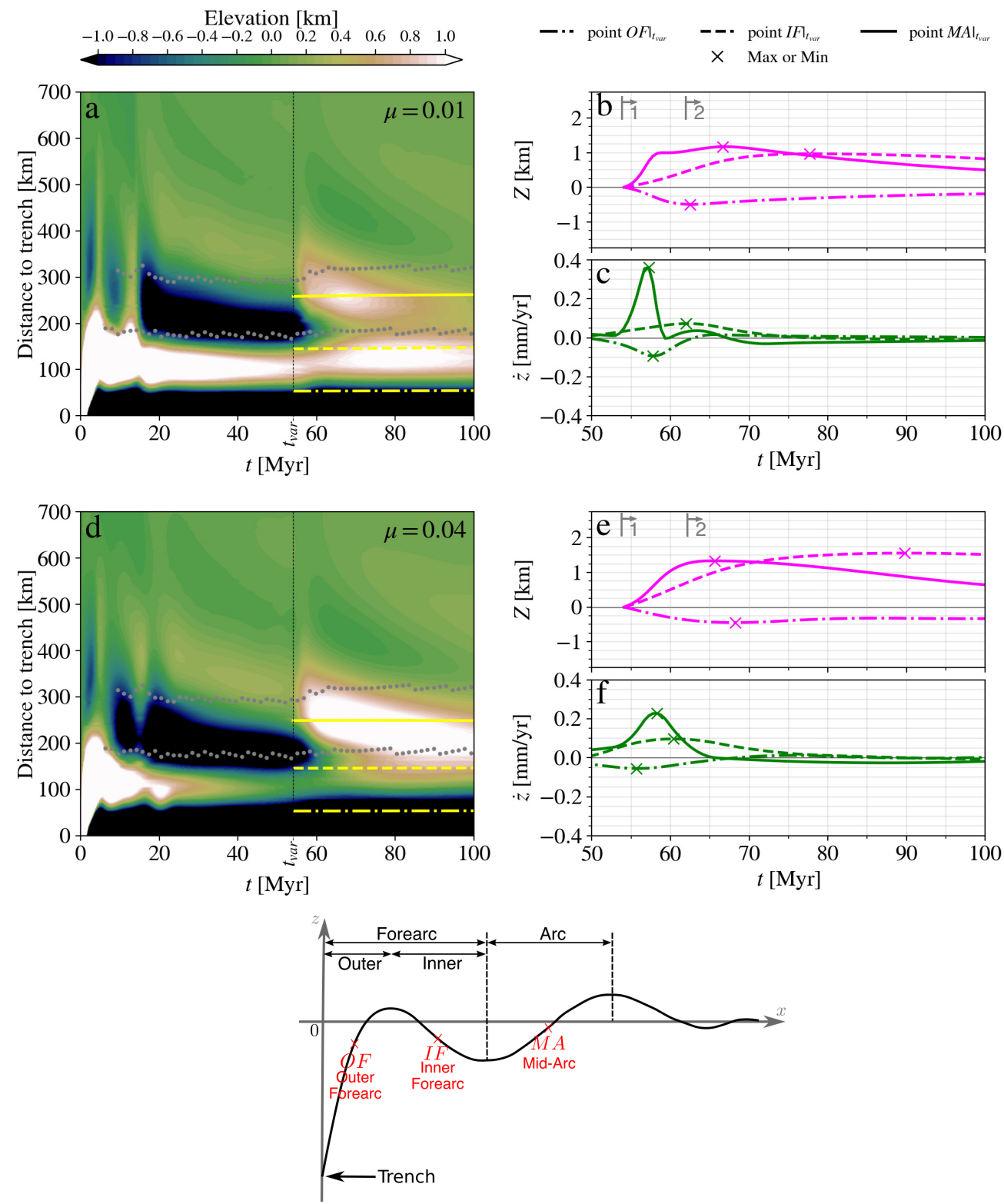

Figure 6. First column: Time-evolution of OP surface elevation in models where overriding plate velocity instantaneously increases from $4 \mathrm{~cm} / \mathrm{yr}$ to $6 \mathrm{~cm} / \mathrm{yr}$ at $t=t_{\text {var }}$. The models have reference plates viscosities and an interplate coefficient of 0.01 (a) and 0.04 (d). The grey dots indicate the estimated location of the arc region, as defined in the main text Sec. 2.1.2

- The yellow lines represent the path of three characteristics points that are the center of the outer forearc $\left(\left.O F\right|_{t_{\text {var }}}\right.$, see sketch), inner forearc $\left(\left.I F\right|_{t_{\text {var }}}\right)$, and mid-arc $\left(\left.M A\right|_{t_{\text {var }}}\right)$ as of $t=t_{\text {var }}$. Second column : Vertical displacement after kinematic change

$Z(t)=z(t)-z\left(t_{\text {var }}\right)(\mathrm{b}, \mathrm{c})$ and rate of elevation change $\dot{z}(t)=\partial_{t} z(t)(\mathrm{c}, \mathrm{f})$ of the three points with time. The crosses indicate the peak displacement $H$ and peak rate of elevation change $\dot{H}$. The grey arrows denote the two stages (defined arbitrarily) following the kinematic change. 

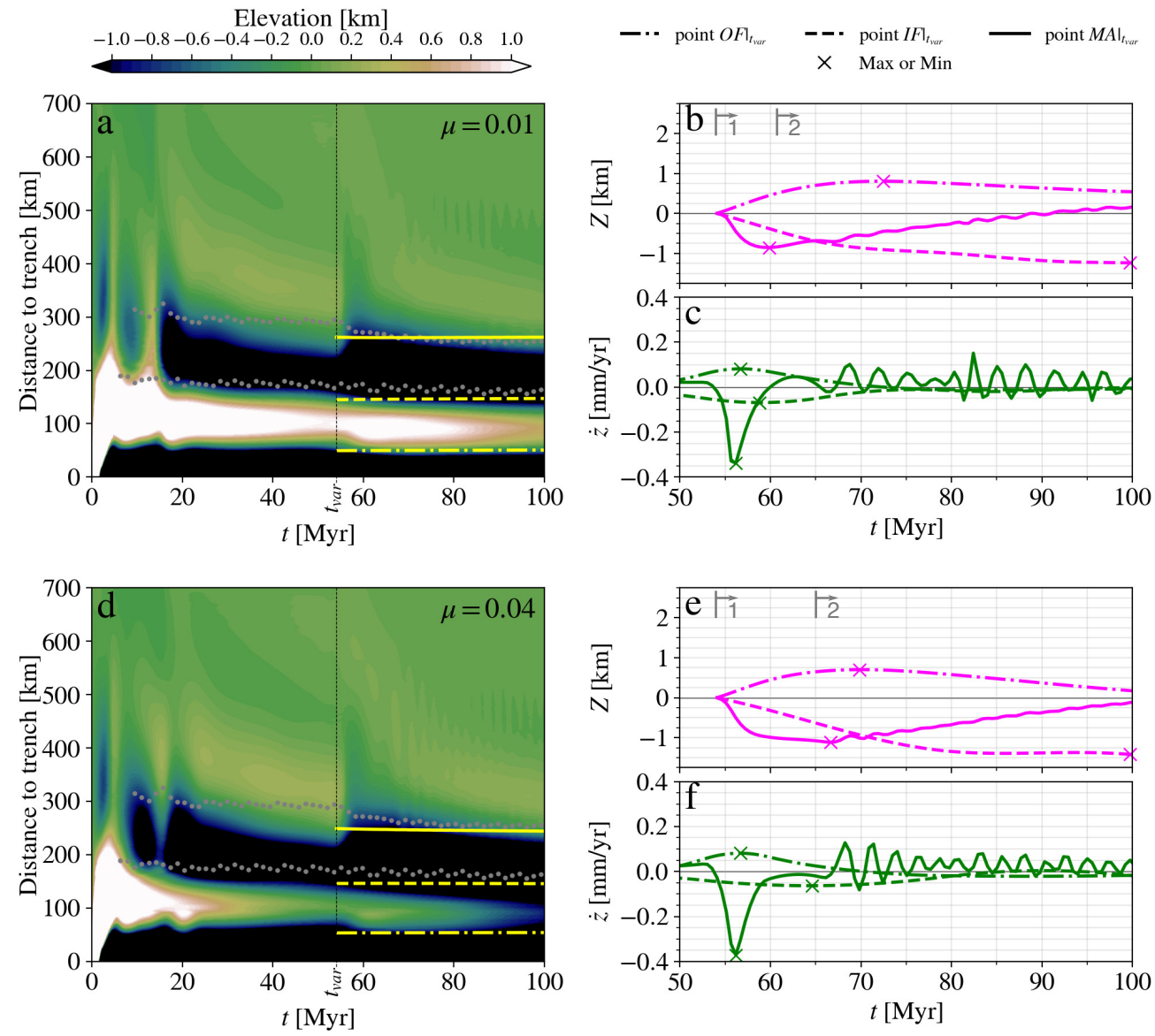

Figure 7. Time-evolution of the overriding plate surface elevation in models where overriding plate velocity instantaneously decreases from $4 \mathrm{~cm} / \mathrm{yr}$ to $2 \mathrm{~cm} / \mathrm{yr}$ at $t=t_{v a r}$. For legend details see Fig. 6. Note that the high-frequency oscillations observed during the second stage $(t \quad \gtrsim 66 \mathrm{Myr})$ arise from the very slow OP velocity which induces a sub-vertical slab and oscillation of the slab geometry about an equilibrium vertical position, that are amplified by intrinsic numerical artifacts. These oscillations should not be considered. 

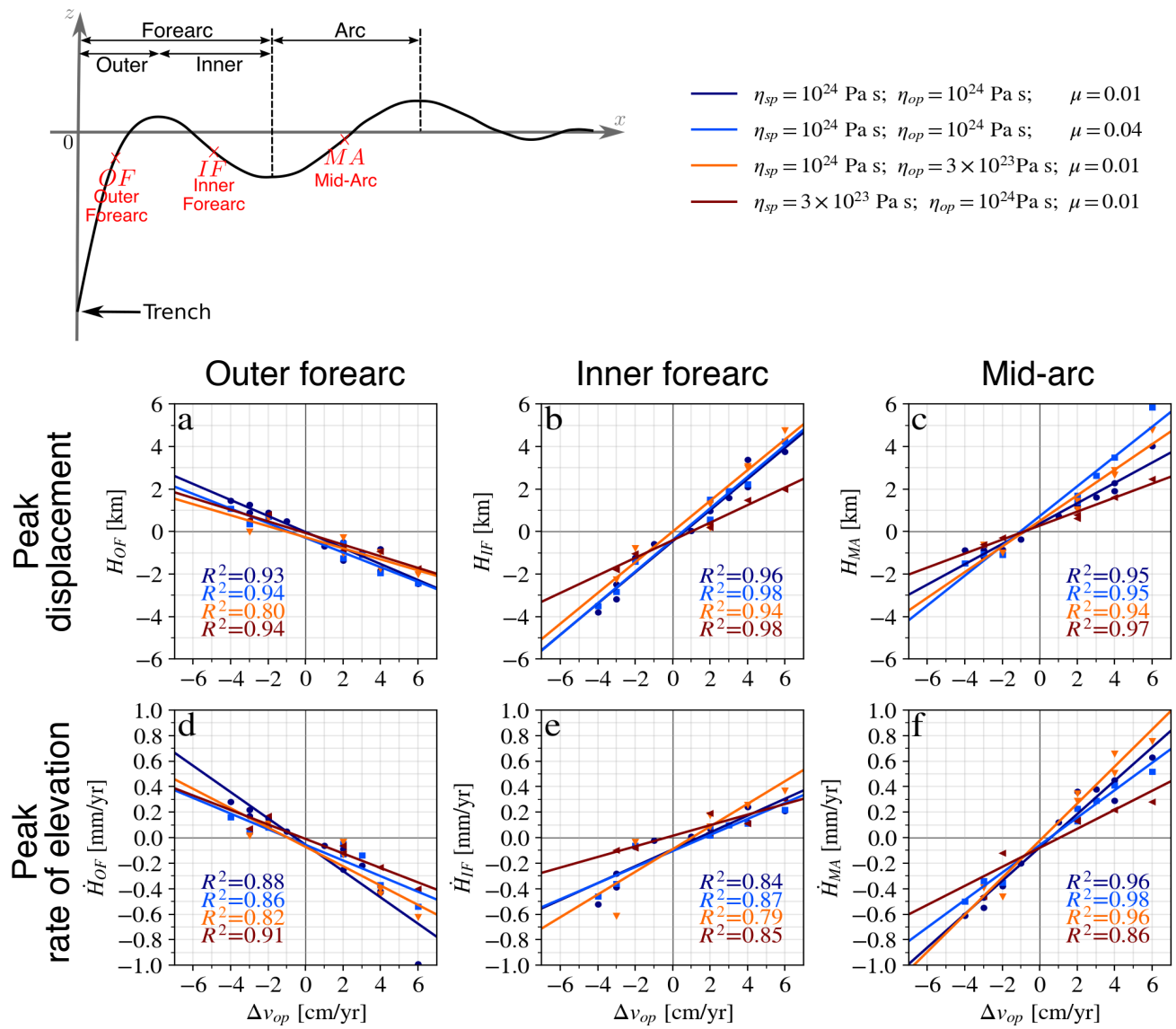

Figure 8. The first row displays the maximum displacement after the change in OP velocity of point $\left.O F\right|_{t_{v a r}}(\mathrm{a})$, that of point $\left.I F\right|_{t_{v a r}}(\mathrm{~b})$, and that of point $\left.M A\right|_{t_{v a r}}$ (c). The second row exhibits the maximum rate of elevation change after the change in OP velocity of point $\left.O F\right|_{t_{v a r}}$ (d), point $\left.I F\right|_{t_{v a r}}(\mathrm{e})$, and that of point $\left.M A\right|_{t_{v a r}}$ (f). Model results are represented by the symbols, and the lines are the associated regression lines with the regression coefficient given on each sub-panel. 


\section{Acknowledgments}

This study was funded by the French ANR (National Research Agency) GAARANTI 17-CE31-0009 and by the French government through ANR under the "Investissements d'avenir, Initiative Sciences Innovation Territoires - MUSE" programme with the reference ANR-16-IDEX-0006. The authors acknowledge Riad Hassani and Serge Lallemand for insightful discussions on subduction dynamics. We thank the two reviewers Philippe Yamato and Laurent Husson for their thoughtful comments that significantly improved the manuscript. The numerical data necessary to replicate the reported results can be found here: https://doi.org/10.5281/zenodo.3685839.

\section{References}

Allen, R., Collier, J., Stewart, A., Henstock, T., Goes, S., Rietbrock, A., \& Team, V. (2019). The role of arc migration in the development of the lesser antilles: A new tectonic model for the cenozoic evolution of the eastern caribbean. Geology, 47(9), 891-895. doi: 10.1130/G46708.1

Alsaif, M., Garel, F., Gueydan, F., \& Davies, D. R. $\quad$ (2020). Upper plate deformation and trench retreat modulated by subduction-driven shallow asthenospheric flows. Earth and Planetary Science Letters, 532, 116013. doi: 10.1016/j.epsl.2019.116013

Arcay, D., Lallemand, S., \& Doin, M.-P. (2008). Back-arc strain in subduction zones: Statistical observations versus numerical modeling. Geochemistry, Geophysics, Geosystems, 9(5). doi: 10.1029/2007GC001875

Arnould, M., Coltice, N., Flament, N., Seigneur, V., \& Müller, R. On the scales of dynamic topography in whole-mantle convection models. Geochemistry, Geophysics, Geosystems, 19(9), 3140-3163. doi: 10.1029/2018GC007516

Becker, T. W., \& O'Connell, R. J. (2001). Predicting plate velocities with mantle circulation models. Geochemistry, Geophysics, Geosystems, 2(12).

Behr, W. M., \& Becker, T. W. (2018). Sediment control on subduction plate speeds. Earth and Planetary Science Letters, 502, 166-173. doi: 10.1016/j.epsl.2018.08 .057

Bellahsen, N., Faccenna, C., \& Funiciello, F. (2005). Dynamics of subduction and plate motion in laboratory experiments: insights into the plate tectonics behavior of the earth. Journal of Geophysical Research: Solid Earth (1978-2012), 110(B1). doi: 10.1029/2004JB002999

Billen, M. I., \& Gurnis, M. (2005). Constraints on subducting plate strength within the kermadec trench. Journal of Geophysical Research: Solid Earth, 110(B5). doi: 10.1029/2004JB003308

Bonnardot, M.-A., Hassani, R., \& Tric, E. (2008). Numerical modelling of lithosphereasthenosphere interaction in a subduction zone. Earth and Planetary Science Letters, 272(34), 698-708. doi: 10.1016/j.epsl.2008.06.009

Braun, J. (2010). The many surface expressions of mantle dynamics. Nature Geoscience, 3(12), 825. doi: 10.1038/ngeo1020

Briaud, A., Agrusta, R., Faccenna, C., Funiciello, F., \& van Hunen, J. (2020). Topographic fingerprint of deep mantle subduction. Journal of Geophysical Research: Solid Earth, e2019JB017962. doi: 10.1029/2019JB017962

Buiter, S., Govers, R., \& Wortel, M. (2001). A modelling study of vertical surface displacements at convergent plate margins. Geophysical Journal International, 147(2), 415-427. doi: 10.1046/j.1365-246X.2001.00545.x

Capitanio, F., Morra, G., \& Goes, S. (2007). Dynamic models of downgoing plate-buoyancy driven subduction: Subduction motions and energy dissipation. $\quad$ Earth and Planetary Science Letters, 262(1), 284-297. doi: 10.1016/j.epsl.2007.07.039

Cazenave, A., Souriau, A., \& Dominh, K. (1989). Global coupling of earth sur- 
face topography with hotspots, geoid and mantle heterogeneities. Nature, 340(6228), 54. doi: 10.1038/340054a0

Cerpa, N. G., Araya, R., Gerbault, M., \& Hassani, R. (2015). Relationship between slab dip and topography segmentation in an oblique subduction zone: Insights from numerical modeling. Geophysical Research Letters, 42(14), 5786-5795. doi: 10.1002/2015GL064047

Cerpa, N. G., Guillaume, B., \& Martinod, J. (2018). The interplay between overriding plate kinematics, slab dip and tectonics. Geophysical Journal International, 215(3), 1789-1802. doi: 10.1093/gji/ggy365

Cerpa, N. G., Hassani, R., Gerbault, M., \& Prévost, J.-H. (2014). A fictitious domain method for lithosphere-asthenosphere interaction: Application to periodic slab folding in the upper mantle. Geochemistry, Geophysics, Geosystems, 15(5), 1852-1877. doi: 10.1002/2014GC005241

Chen, Z., Schellart, W. P., Duarte, J. C., \& Strak, V. (2017). Topography of the overriding plate during progressive subduction: A dynamic model to explain forearc subsidence. Geophysical Research Letters, 44(19), 9632-9643. doi: 10.1002/2017GL074672

Clark, S., Stegman, D., \& Müller, R. $\quad$ (2008). Episodicity in back-arc tectonic regimes. Physics of the Earth and Planetary Interiors, 171(1), 265-279. doi: 10.1016/j.pepi.2008.04.012

Conrad, C. P., \& Lithgow-Bertelloni, C. (2002). How mantle slabs drive plate tectonics. Science, 298(5591), 207-209.

Crameri, F., Lithgow-Bertelloni, C., \& Tackley, P. J. (2017). The dynamical control of subduction parameters on surface topography. Geochemistry, Geophysics, Geosystems, 18(4), 1661-1687. doi: 10.1002/2017GC006821

Crameri, F., \& Tackley, P. J. (2015). Parameters controlling dynamically selfconsistent plate tectonics and single-sided subduction in global models of mantle convection. Journal of Geophysical Research: Solid Earth, 120(5), 3680-3706. doi: 10.1002/2014JB011664

Dasgupta, R., \& Mandal, N. (2018). Surface topography of the overriding plates in bi-vergent subduction systems: A mechanical model. Tectonophysics, 746 , 280-295. doi: 10.1016/j.tecto.2017.08.008

Davies, G. F. (1981). Regional compensation of subducted lithosphere: effects on geoid, gravity and topography from a preliminary model. Earth and Planetary Science Letters, 54(3), 431-441. doi: 10.1016/0012-821X(81)90059-5

Dávila, F. M., \& Lithgow-Bertelloni, C. (2013). Dynamic topography in south america. Journal of South American Earth Sciences, 43, 127-144. doi: 10.1016/j .jsames.2012.12.002

Duarte, J. C., Schellart, W. P., \& Cruden, A. R. (2013). Three-dimensional dynamic laboratory models of subduction with an overriding plate and variable interplate rheology. Geophysical Journal International, ggt257.

Duggen, S., Hoernle, K., Van Den Bogaard, P., Rüpke, L., \& Morgan, J. P. (2003). Deep roots of the messinian salinity crisis. Nature, 422(6932), 602. doi: 10 $.1038 /$ nature01553

Elsasser, W. M. (1969). Convection and stress propagation in the upper mantle. doi: $10.1029 / J B 076 i 005 p 01101$

Faccenna, C., Becker, T. W., Conrad, C. P., \& Husson, L. (2013). Mountain building and mantle dynamics. Tectonics, 32(1), 80-93. doi: 10.1029/2012TC003176

Faccenna, C., Oncken, O., Holt, A. F., \& Becker, T. W. (2017). Initiation of the andean orogeny by lower mantle subduction. Earth and Planetary Science Letters, 463, 189-201. doi: 10.1016/j.epsl.2017.01.041

Forte, A., Peltier, W., Dziewonski, A., \& Woodward, R. (1993). Dynamic surface topography: A new interpretation based upon mantle flow models derived from seismic tomography. Geophysical Research Letters, 20(3), 225-228. doi: 10.1029/93GL00249 
Fukao, Y., \& Obayashi, M. (2013). Subducted slabs stagnant above, penetrating through, and trapped below the $660 \mathrm{~km}$ discontinuity. Journal of Geophysical Research: Solid Earth, 118(11), 5920-5938. doi: 10.1002/2013JB010466

Funiciello, F., Morra, G., Regenauer-Lieb, K., \& Giardini, D. (2003). Dynamics of retreating slabs: 1 . insights from two-dimensional numerical experiments. Journal of Geophysical Research: Solid Earth (1978-2012), 108(B4). doi: 10.1029/ 2001JB000898

Garel, F., Goes, S., Davies, D., Davies, J., Kramer, S., \& Wilson, C. (2014). Interaction of subducted slabs with the mantle transition-zone: A regime diagram from 2-d thermo-mechanical models with a mobile trench and an overriding plate. Geochemistry, Geophysics, Geosystems. doi: 10.1002/2014GC005257

Gerardi, G., \& Ribe, N. M. (2018). Boundary element modeling of two-plate interaction at subduction zones: Scaling laws and application to the aleutian subduction zone. Journal of Geophysical Research: Solid Earth, 123(6), 52275248. doi: 10.1002/2017JB015148

Gerya, T. V., Connolly, J. A., \& Yuen, D. A. (2008). Why is terrestrial subduction one-sided? Geology, 36(1), 43-46.

Goes, S., Agrusta, R., Van Hunen, J., \& Garel, F. $\quad$ (2017). Subductiontransition zone interaction: A review. Geosphere, 13(3), 644-664. doi: 10.1130/GES01476.1

Goes, S., Capitanio, F. A., Morra, G., Seton, M., \& Giardini, D. (2011). Signatures of downgoing plate-buoyancy driven subduction in cenozoic plate motions. Physics of the Earth and Planetary Interiors, 184(1), 1-13. doi: 10.1016/j.pepi.2010.10.007

Guillaume, B., Hertgen, S., Martinod, J., \& Cerpa, N. ～(2018). Slab dip, surface tectonics: How and when do they change following an acceleration/slow down of the overriding plate? Tectonophysics, 726, 110-120. doi: 10.1016/j.tecto.2018.01.030

Gurnis, M. (1993). Phanerozoic marine inundation of continents driven by dynamic topography above subducting slabs. Nature, 364(6438), 589. doi: 10.1038/ $364589 \mathrm{a} 0$

Hampel, A., \& Pfiffner, A. (2006). Relative importance of trenchward upper plate motion and friction along the plate interface for the topographic evolution of subduction-related mountain belts. Geological Society, London, Special Publications, 253(1), 105-115. doi: 10.1144/GSL.SP.2006.253.01.05

Hassani, R., Jongmans, D., \& Chéry, J. (1997). Study of plate deformation and stress in subduction processes using two-dimensional numerical models. Journal of Geophysical Research: Solid Earth, 102(B8), 1795117965. doi: 10.1029/ 97JB01354

Henry, H., Regard, V., Pedoja, K., Husson, L., Martinod, J., Witt, C., \& Heuret, A. (2014). Upper pleistocene uplifted shorelines as tracers of (local rather than global) subduction dynamics. Journal of Geodynamics, 78, 8-20. doi: 10.1016/j.jog.2014.04.001

Hertgen, S., Yamato, P., Guillaume, B., Magni, V., Schliffke, N., \& van Hunen, J. (2020). Influence of the thickness of the overriding plate on convergence zone dynamics. Geochemistry, Geophysics, Geosystems, e2019GC008678.

Heuret, A., \& Lallemand, S. (2005). Plate motions, slab dynamics and back-arc deformation. Physics of the Earth and Planetary Interiors, 149(1), 31-51. doi: 10.1016/j.pepi.2004.08.022

Hoggard, M. J., White, N., \& Al-Attar, D. (2016). Global dynamic topography observations reveal limited influence of large-scale mantle flow. Nature Geoscience, 9(6), 456. doi: 10.1038/NGEO2709

Holt, A., Becker, T., \& Buffett, B. (2015). Trench migration and overriding plate stress in dynamic subduction models. Geophysical Journal International, 201 (1), 172-192. doi: 10.1093/gji/ggv011 
Husson, L. (2006). Dynamic topography above retreating subduction zones. Geology, $34(9), 741-744$. doi: $10.1130 / \mathrm{G} 22436.1$

Husson, L. (2012). Trench migration and upper plate strain over a convecting mantle. Physics of the Earth and Planetary Interiors, 212, 32-43.

Husson, L., Conrad, C., \& Faccenna, C. (2012). Plate motions, andean orogeny, and volcanism above the south atlantic convection cell. Earth and Planetary Science Letters, 317, 126-135. doi: 10.1016/j.epsl.2011.11.040

Iturralde-Vinent, M., \& MacPhee, R. D. (1999). Paleogeography of the caribbean region: implications for cenozoic biogeography. bulletin of the amnh: no. 238 .

Lallemand, S., Heuret, A., Faccenna, C., \& Funiciello, F. （2008). Subduction dynamics as revealed by trench migration. Tectonics, 27(3). doi: 10.1029/2007TC002212

Lallemand, S., \& Lebrun, J. (2017). Asymmetric grenada basin and its relation with aves ridge and lesser antilles arc: Preliminary results from cruise garanti. In Agu fall meeting abstracts.

Lamb, S., \& Davis, P. (2003). Cenozoic climate change as a possible cause for the rise of the andes. Nature, 425(6960), 792-797. doi: 10.1038/nature02049

Loiselet, C., Husson, L., \& Braun, J. (2009). From longitudinal slab curvature to slab rheology. Geology, 37(8), 747-750. doi: 10.1130/G30052A.1

Marivaux, L., Vélez-Juarbe, J., Merzeraud, G., Pujos, F., Viñola López, L. W., Boivin, M., ... others (2020). Early oligocene chinchilloid caviomorphs from puerto rico and the initial rodent colonization of the west indies. Proceedings of the Royal Society B, 287(1920), 20192806. doi: 10.1098/rspb.2019.2806

Martinod, J., Regard, V., Letourmy, Y., Henry, H., Hassani, R., Baratchart, S., \& Carretier, S. (2016). How do subduction processes contribute to forearc andean uplift? insights from numerical models. Journal of Geodynamics, 96, 6-18. doi: 10.1016/j.jog.2015.04.001

McKenzie, D. P. (1969). Speculations on the consequences and causes of plate motions. Geophysical Journal International, 18(1), 1-32. doi: 10.1111/j.1365 -246X.1969.tb00259.x

Mitrovica, J., Beaumont, C., \& Jarvis, G. (1989). Tilting of continental interiors by the dynamical effects of subduction. Tectonics, 8(5), 1079-1094. doi: 10.1029/ TC008i005p01079

Morra, G., \& Regenauer-Lieb, K. (2006). A coupled solid-fluid method for modelling subduction. Philosophical magazine, 86(21-22), 3307-3323. doi: 10.1080/ 14786430500256359

Noda, A. (2016). Forearc basins: Types, geometries, and relationships to subduction zone dynamics. Bulletin, 128(5-6), 879-895. doi: 10.1130/B31345.1

Pedoja, K., Husson, L., Regard, V., Cobbold, P. R., Ostanciaux, E., Johnson, M. E., ... others (2011). Relative sea-level fall since the last interglacial stage: are coasts uplifting worldwide? Earth-Science Reviews, 108(1-2), 1-15. doi: 10.1016/j.earscirev.2011.05.002

Pedoja, K., Ortlieb, L., Dumont, J.-F., Lamothe, M., Ghaleb, B., Auclair, M., \& Labrousse, B. (2006). Quaternary coastal uplift along the talara arc (ecuador, northern peru) from new marine terrace data. Marine Geology, 228(1-4), 73-91. doi: 10.1016/j.margeo.2006.01.004

Regalla, C., Fisher, D. M., Kirby, E., \& Furlong, K. P. (2013). Relationship between outer forearc subsidence and plate boundary kinematics along the northeast japan convergent margin. Geochemistry, Geophysics, Geosystems, 14 (12), 5227-5243. doi: 10.1002/2013GC005008

Ribe, N. M. (2010). Bending mechanics and mode selection in free subduction: a thin-sheet analysis. Geophysical Journal International, 180(2), 559-576. doi: 10.1111/j.1365-246X.2009.04460.x

Riel, N., Capitanio, F. A., \& Velic, M. (2017). Numerical modeling of stress and topography coupling during subduction: Inferences on global vs. regional ob- 
servables interpretation. Tectonophysics. doi: 10.1016/j.tecto.2017.07.023

Saillard, M., Audin, L., Rousset, B., Avouac, J.-P., Chlieh, M., Hall, S. R., .. Farber, D. (2017). From the seismic cycle to long-term deformation: linking seismic coupling and quaternary coastal geomorphology along the andean megathrust. Tectonics, 36(2), 241-256. doi: 10.1002/2016TC004156

Schellart, W. P. (2008). Kinematics and flow patterns in deep mantle and upper mantle subduction models: Influence of the mantle depth and slab to mantle viscosity ratio. Geochemistry, Geophysics, Geosystems, 9(3). doi: 10.1029/2004JB002970

Sdrolias, M., \& Müller, R. (2006). Controls on back-arc basin formation. Geochemistry, Geophysics, Geosystems, 7(4). doi: 10.1029/2005GC001090

Shemenda, A. I. (1993). Subduction of the lithosphere and back arc dynamics: Insights from physical modeling. Journal of Geophysical Research: Solid Earth (1978-2012), 98(B9), 16167-16185. doi: 10.1029/93JB01094

Shephard, G., Müller, R., Liu, L., \& Gurnis, M. (2010). Miocene drainage reversal of the amazon river driven by plate-mantle interaction. Nature Geoscience, 3(12), 870. doi: 10.1038/NGEO1017

Sobolev, S. V., \& Babeyko, A. Y. (2005). What drives orogeny in the andes? Geology, 33(8), 617-620. doi: 10.1130/G21557AR.1

Sobolev, S. V., \& Brown, M. (2019). Surface erosion events controlled the evolution of plate tectonics on earth. Nature, 570(7759), 52. doi: 10.1038/s41586-019 $-1258-4$

Somoza, R., \& Ghidella, M. E. (2012). Late cretaceous to recent plate motions in western south america revisited. Earth and Planetary Science Letters, 331, 152-163. doi: 10.1016/j.epsl.2012.03.003

Syracuse, E. M., \& Abers, G. A. (2006). Global compilation of variations in slab depth beneath arc volcanoes and implications. Geochemistry, Geophysics, Geosystems, 7(5). doi: 10.1029/2005GC001045

Wu, B., Conrad, C., Heuret, A., Lithgow-Bertelloni, C., \& Lallemand, S. （2008). Reconciling strong slab pull and weak plate bending: The plate motion constraint on the strength of mantle slabs. Earth and Planetary Science Letters, 272(1), 412-421. doi: 10.1016/j.epsl.2008.05.009

Zahirovic, S., Müller, R. D., Seton, M., \& Flament, N. (2015). Tectonic speed limits from plate kinematic reconstructions. Earth and Planetary Science Letters, 418, 40-52. doi: 10.1016/j.epsl.2015.02.037

Zhong, S., \& Gurnis, M. (1992). Viscous flow model of a subduction zone with a faulted lithosphere: long and short wavelength topography, gravity and geoid. Geophysical Research Letters, 19(18), 1891-1894. doi: 10.1029/92GL02142

Zhong, S., \& Gurnis, M. (1994). Controls on trench topography from dynamic models of subducted slabs. Journal of Geophysical Research: Solid Earth, 99(B8), 15683-15695. doi: 10.1029/94JB00809 


\section{Supporting Information for "Overriding-plate velocity control on surface topography in 2 -d models of subduction zones"}

Nestor G. Cerpa ${ }^{1,2}$, Diane Arcay ${ }^{1}$

${ }^{1}$ Géosciences Montpellier, Universtité de Montpellier, CNRS, Universtité des Antilles, Montpellier, France

${ }^{2}$ Géoazur, Université Côte d'Azur, CNRS, Observatoire de la Côte d'Azur, IRD, Valbonne, France

Contents of this file

1. Text S1

2. Movies S1 to S2

3. Figures $\mathrm{S} 1$ to $\mathrm{S} 6$

4. Table S1 


\section{Text}

\section{Text S1 : Governing equations and numerical approach}

The governing equations for the quasi-static evolution of lithospheric plates occupying at time $t$ a physical domain $\Omega_{l}^{t} \subset \mathbb{R}^{2}$ are

$$
\nabla \cdot \boldsymbol{\sigma}+\rho_{l} \boldsymbol{g}=\mathbf{0} \text { in } \Omega_{l}^{t}
$$

$\frac{D \boldsymbol{\sigma}}{D t}=2 G \boldsymbol{d}+\lambda \operatorname{tr} \boldsymbol{d} \boldsymbol{I}-\frac{G}{\eta_{l}} \operatorname{dev} \boldsymbol{\sigma} \quad$ in $\Omega_{l}^{t}$,

where $\boldsymbol{\sigma}$ is Cauchy stress tensor, $\boldsymbol{g}$ is gravity acceleration vector, and $\rho_{l}$ is density of lithospheric plates. The symbol $D \cdot / D t$ describes an objective time derivative. $\boldsymbol{d}=$ $\frac{1}{2}\left(\nabla \dot{\boldsymbol{u}}+\nabla \dot{\boldsymbol{u}}^{T}\right)$ is Eulerian strain rate tensor with $\dot{\boldsymbol{u}}$ the velocity field in the plates. tr and dev are the trace and deviatoric parts of a second order tensor, respectively. $\boldsymbol{I}$ is identity tensor. $\lambda$ and $G$ are the Lamé parameters and $\eta_{l}$ is viscosity of the lithospheric plates. Note that if $\eta \rightarrow \infty$, Eq. (2) describes Hooke's law.

The contact between the two lithospheric plates or between a plate and a rigid foundation is described by the Signorini contact conditions defined with a Coulomb friction law as

$$
\begin{array}{r}
\delta \dot{u}_{n} \leq 0, \sigma_{n} \leq 0, \delta \dot{u}_{n} \sigma_{n}=0 \quad \text { on } \Gamma_{c} \\
\left|\sigma_{t}\right| \leq-\mu \sigma_{n} \text { if } \delta \dot{u}_{t}=0 \quad \text { on } \Gamma_{c} \\
\sigma_{t}=\mu \sigma_{n} \frac{\delta \dot{u}_{t}}{\left|\delta \dot{u}_{t}\right|} \text { if } \delta \dot{u}_{t} \neq 0 \quad \text { on } \Gamma_{c}
\end{array}
$$

where $\delta \dot{u}_{n}$ and $\delta \dot{u}_{t}$ are, respectively, the normal and tangential components of the relative velocity between a point of one plate and its projection onto the other plate or onto the 
rigid foundation, $\mu$ is Coulomb friction coefficient, $\sigma_{n}$ and $\sigma_{t}$ are normal and tangential stresses, respectively.

In the mantle (domain $\Omega_{m} \subset \mathbb{R}^{2}$ ), we solve the incompressible Stokes equations and we use a Newtonian constitutive law :

$$
\begin{array}{rr}
\boldsymbol{\nabla} \cdot \boldsymbol{\tau}+\boldsymbol{\nabla} P+\rho_{m} \boldsymbol{g}=0 & \text { in } \Omega_{m}, \\
\boldsymbol{\nabla} \cdot \boldsymbol{v}=0 & \text { in } \Omega_{m}, \\
\boldsymbol{\tau}=2 \eta_{m} \dot{\boldsymbol{\epsilon}} & \text { in } \Omega_{m}
\end{array}
$$

where $\boldsymbol{\tau}$ is the deviatoric stress tensor, $\boldsymbol{v}$ is velocity field, $P$ total pressure. $\rho_{m}$ is density of mantle and $\eta_{m}$ its viscosity. $\dot{\boldsymbol{\epsilon}}=\frac{1}{2}\left(\nabla \boldsymbol{v}+\nabla \boldsymbol{v}^{T}\right)$ is strain-rate tensor.

On the plates-mantle interfaces $\Gamma_{l m}$ we assume continuity of velocity fields (fullcoupling) and continuity of the traction vector (principle of action-reaction):

$$
\begin{array}{rr}
\boldsymbol{v}=\boldsymbol{u} & \text { on } \Gamma_{l a} \\
(\boldsymbol{\tau}+P \boldsymbol{I}) \cdot \boldsymbol{n}=\boldsymbol{\sigma} \cdot \boldsymbol{n} & \text { on } \Gamma_{l a}
\end{array}
$$

where $\boldsymbol{n}$ is unit vector normal to $\Gamma_{l a}$ with outwards orientation relative to $\Omega_{l}^{t}$.

We adopt the numerical modeling approach that has been described in details in ? (?) and ? (?). We solve Eqs. (1)-(5) in the plate with a Lagrangian solid solver (?, ?), and Eqs. (6)-(8) in the upper mantle with an Eulerian Stokes solver. Thus, as described below, two separate sets of boundary conditions are required for the two solvers. The continuity condition (9)-(10) are enforced in the Stokes solver by a fictitious domain method and in the solid solver as Neumann boundary conditions on the immersed interfaces, respectively. To ensure the stability of the fluid-solid coupling we use a semi-explicit coupling scheme. 
Two independent meshes are used to discretize spatially the lithospheric plates and the upper mantle in order to solve the two mechanical problems described above. The plates are discretized with an unstructured triangular mesh of average size 15-km. Note that we use a finer mesh $(2-5 \mathrm{~km})$ in the uppermost part of the overriding plate to capture the short-wavelength topography variations. The velocities, when imposed, are applied as Dirichlet boundary conditions. The top of the plates are free. On the boundaries of the plates that are immersed in the mantle, the lithostatic pressure and mantle-viscous forces (calculated via the fictitious domain method) are imposed as Neumann boundary condition. The upper mantle is discritized with a uniform Cartesian grid with cell sizes of $10-\mathrm{km}$. The width of the mantle domain is set to the initial sum of plates' length $(8200 \mathrm{~km})$. The vertical sides in the mantle domain are stress-free (open). The top of the mantle domain which lies at a $20 \mathrm{~km}$-depth is free-slip. The boundary condition on this boundary of the mantle domain does not affect the general subduction dynamics (?, ?). Most importantly such a boundary condition imposed at the top of the upper-mantle domain does not affect the vertical deformation of the plates, and their surfaces remain free. The velocity is imposed to zero (no-slip) on the bottom boundary of the mantle domain which lies at a $660-\mathrm{km}$ depth. This boundary condition is consistent with the imposition of a rough and rigid foundation at a 660-km depth in the solid solver.

\section{Movies}

Movie S1: Time-evolution of the free model with reference rheological parameters. At the top, the color scale indicates the dynamic pressure in the upper mantle and the arrows represent the mantle velocity field. At the bottom, the evolution of OP and SP kinematics is given by the solid and dashed lines, respectively, as in Fig. 1 in the main text.

February 27, 2020, 5:58pm 
Movie S2: Time-evolution of the SP-free model with reference parameters. The other legend details are as in Movie S1.

\section{Figures}

Text for Figure S2: The figure shows the relationship between the surface topography (see Fig. 4 in the main text) and the geometry of the subduction interface which also illustrates the interplate force. The models with a relative low interplate friction coefficient exhibit the downdip drag of the base of the OP in contact with the slab when the former is in extension (a). On the contrary, the base of the OP is uplifted in case of an OP in compression (c). A weak overriding plate deflection is observed in the neutral regime (b). The models with $\mu=0.04$ with $v_{o p}=2 \mathrm{~cm} / \mathrm{yr}$ shows that although the OP tectonic regime is neutral far from the trench, the plate interface is dragged downdip by the enhanced shear stresses producing an overall deflection similar to the cases where the $\mathrm{OP}$ is in extension in models with a low $\mu(\mathrm{d})$. The downward dragging of the OP base by shear is partly compensated for moderate compressive stresses (e).

Text for Figure S6: We have tested the consequences of a progressive change in $v_{o p}$ on its associated OP surface vertical motion and reported the results in Fig. S6. The time over which $v_{o p}$ is (linearly) varied is denoted $\Delta t_{v a r}$. For a same value of velocity change, the peak displacements of points $\left.O F\right|_{t_{v a r}}$ and $\left.M A\right|_{t_{v a r}}$ are mostly insensitive to $\Delta t_{v a r}$, because these peaks represent the steady-state accommodation to new boundary conditions. The peak rates of elevation change, on the other hand, highly depends on $\Delta t_{\text {var }}$. The transient first stage is less and less prominent with the increase of $\Delta t_{v a r}$. For $\Delta t_{v a r}=5 \mathrm{Myr}$, the maximum rates of points $\left.O F\right|_{t_{v a r}}$ and $\left.M A\right|_{t_{v a r}}$ are $55 \%$ and $52 \%$, respectively, of that when the change in OP-velocity is instantaneous. By increasing $\Delta t_{v a r}$, the peak rates 
$\mathrm{X}-6$

may tend towards a plateau. For $\Delta t_{v a r}=30 \mathrm{Myr}$, the peak rates are only about $20 \%$ $\left(\dot{H}_{O F} \simeq 0.01 \mathrm{~mm} / \mathrm{yr}\right)$ and $10 \%\left(\dot{H}_{M A} \simeq 0.04 \mathrm{~mm} / \mathrm{yr}\right)$ of that for $\Delta t_{v a r}=0 \mathrm{Myr}$.

\section{Table S1}

February 27, 2020, 5:58pm 
- $\eta_{s p}=10^{24} \mathrm{~Pa} \mathrm{~s} ; \quad \eta_{o p}=10^{24} \mathrm{~Pa} \mathrm{~s} ; \quad \mu=0.01$

- $\eta_{s p}=10^{24} \mathrm{~Pa} \mathrm{~s} ; \quad \eta_{o p}=10^{24} \mathrm{~Pa} \mathrm{~s} ; \quad \mu=0.04$

- $\eta_{s p}=10^{24} \mathrm{~Pa} \mathrm{~s} ; \quad \eta_{o p}=3 \times 10^{23} \mathrm{~Pa} \mathrm{~s} ; \mu=0.01$

- $\eta_{s p}=3 \times 10^{23} \mathrm{~Pa} \mathrm{~s} ; \eta_{o p}=10^{24} \mathrm{~Pa} \mathrm{~s} ; \quad \mu=0.01$
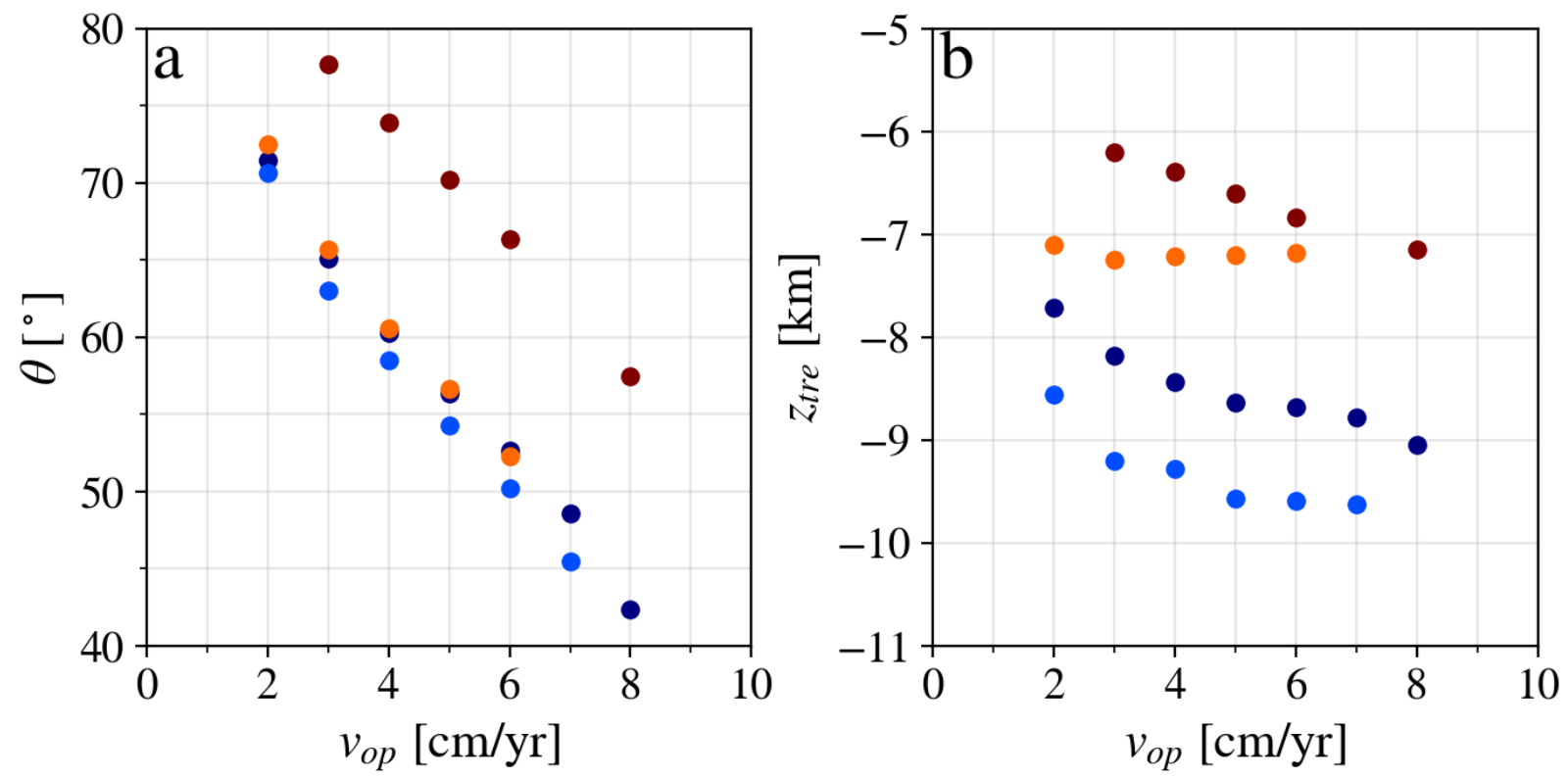

Figure S1. Time-averaged mean slab $\operatorname{dip} \theta$ (a) and trench elevation $z_{\text {tre }}(\mathrm{b})$ during the quasisteady state phase in models with constant overriding plate velocity. The mean slab dip is defined as the mean angle of the top of the subducting plate between a 200 and a 400-km depth. The time-average window is the last 20 Myrs of each model. 


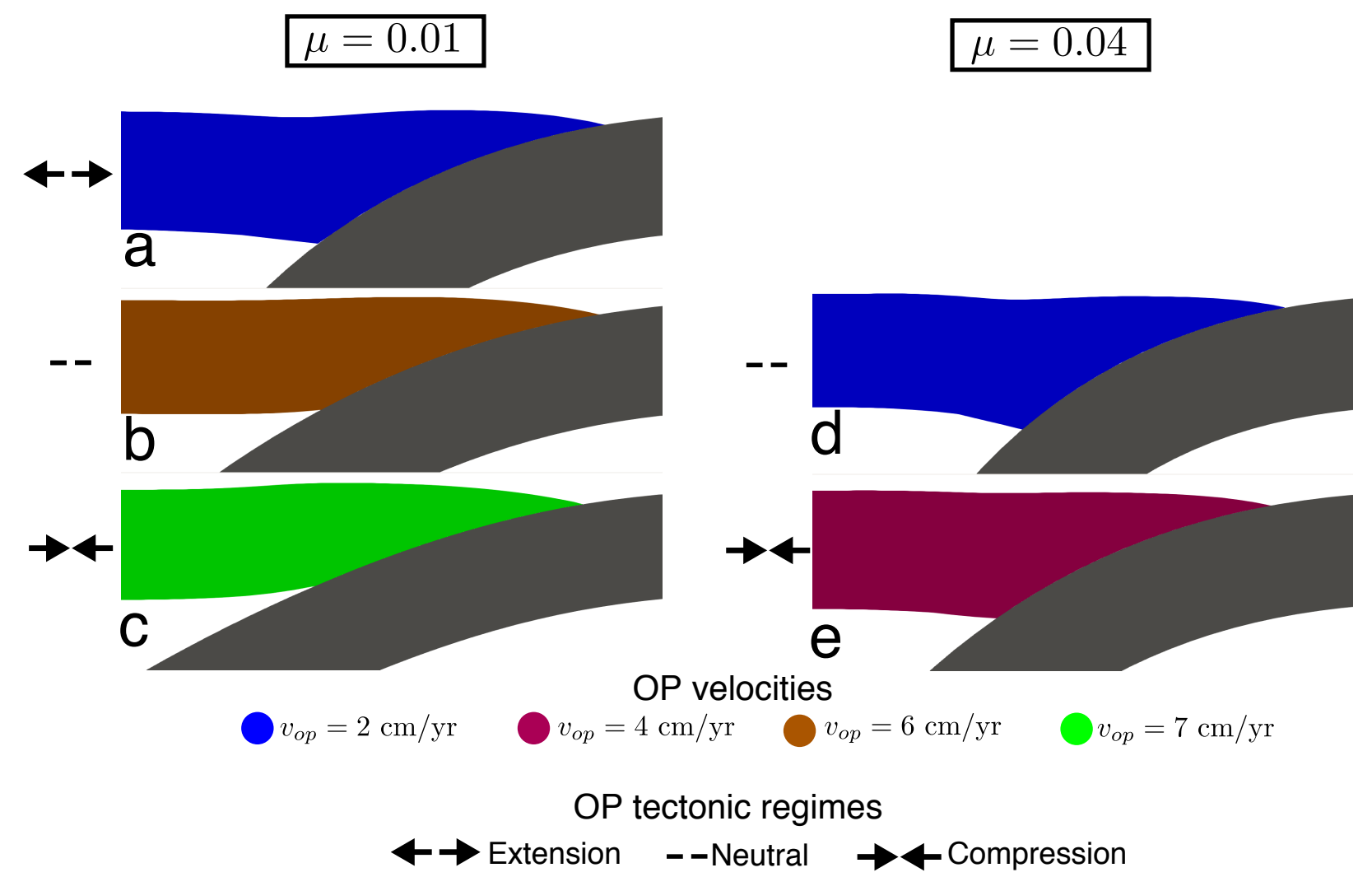

Figure S2. Geometry of the plate interface in models with constant OP velocity during the quasi-steady state phase. We have reported on the figures the average OP tectonic regime. The colors represent the values of $\mathrm{OP}$ velocities and correspond to colors in Fig. 4 in the main text. 
$v_{o p}=[4 ; 6] \mathrm{cm} / \mathrm{yr}$
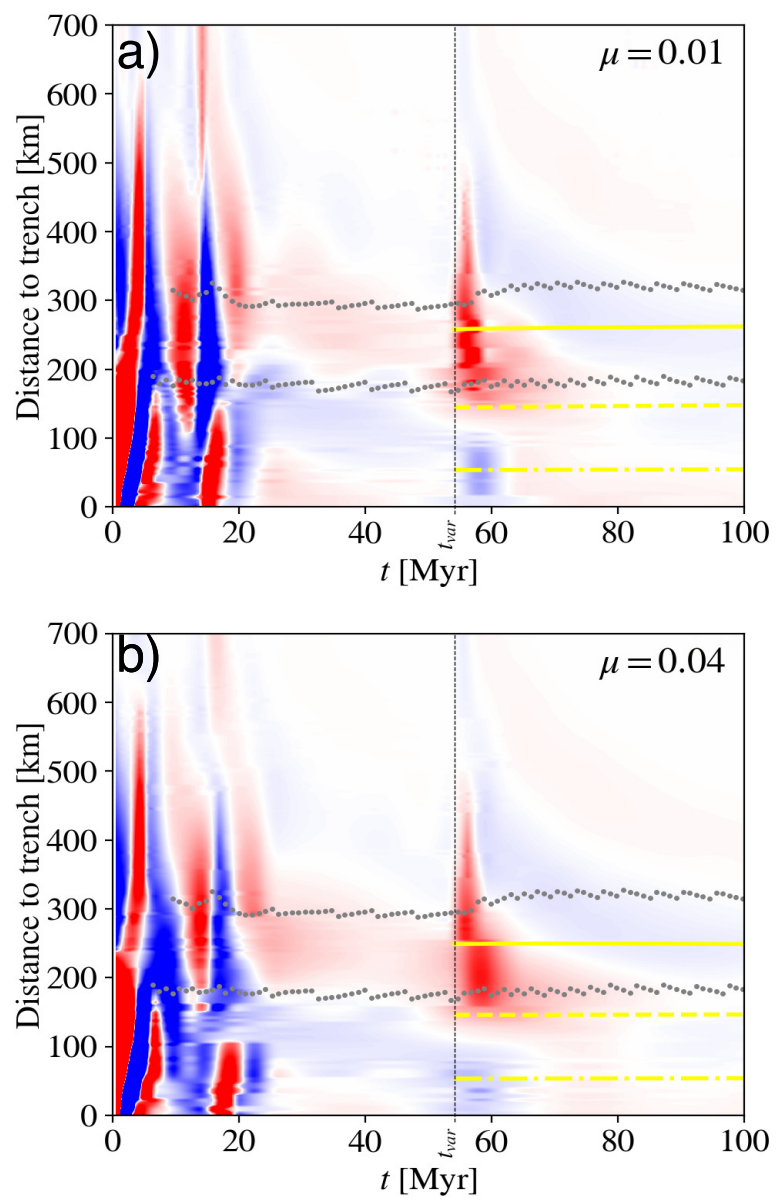

$v_{o p}=[4 ; 2] \mathrm{cm} / \mathrm{yr}$
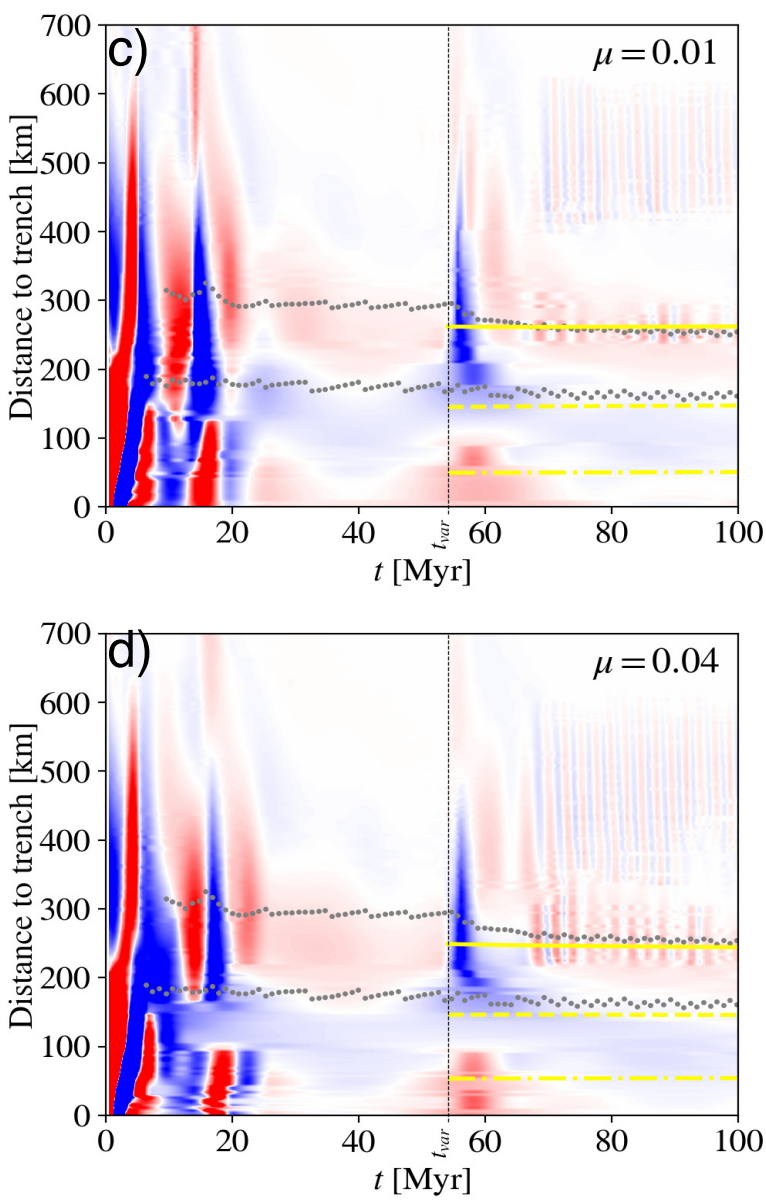

Figure S3. Time-evolution map of rate of elevation change in models where the OP-velocity changes from 4 to $6 \mathrm{~cm} / \mathrm{yr}$ (first column) and from 4 to $2 \mathrm{~cm} / \mathrm{yr}$ (second column). The two cases with a low friction coefficient (first row) and a higher friction coefficient (second row) are tested for each kinematic scenario. The grey dots indicate the estimated location of the arc region. The yellow lines indicate the location of the points $\left.O F\right|_{t_{v a r}}$ (left-end of the dash-dotted line), $\left.I F\right|_{t_{v a r}}$ (left-end of the dashed line), $\left.M A\right|_{t_{v a r}}$ (left-end of the solid line), as defined in the main text. 


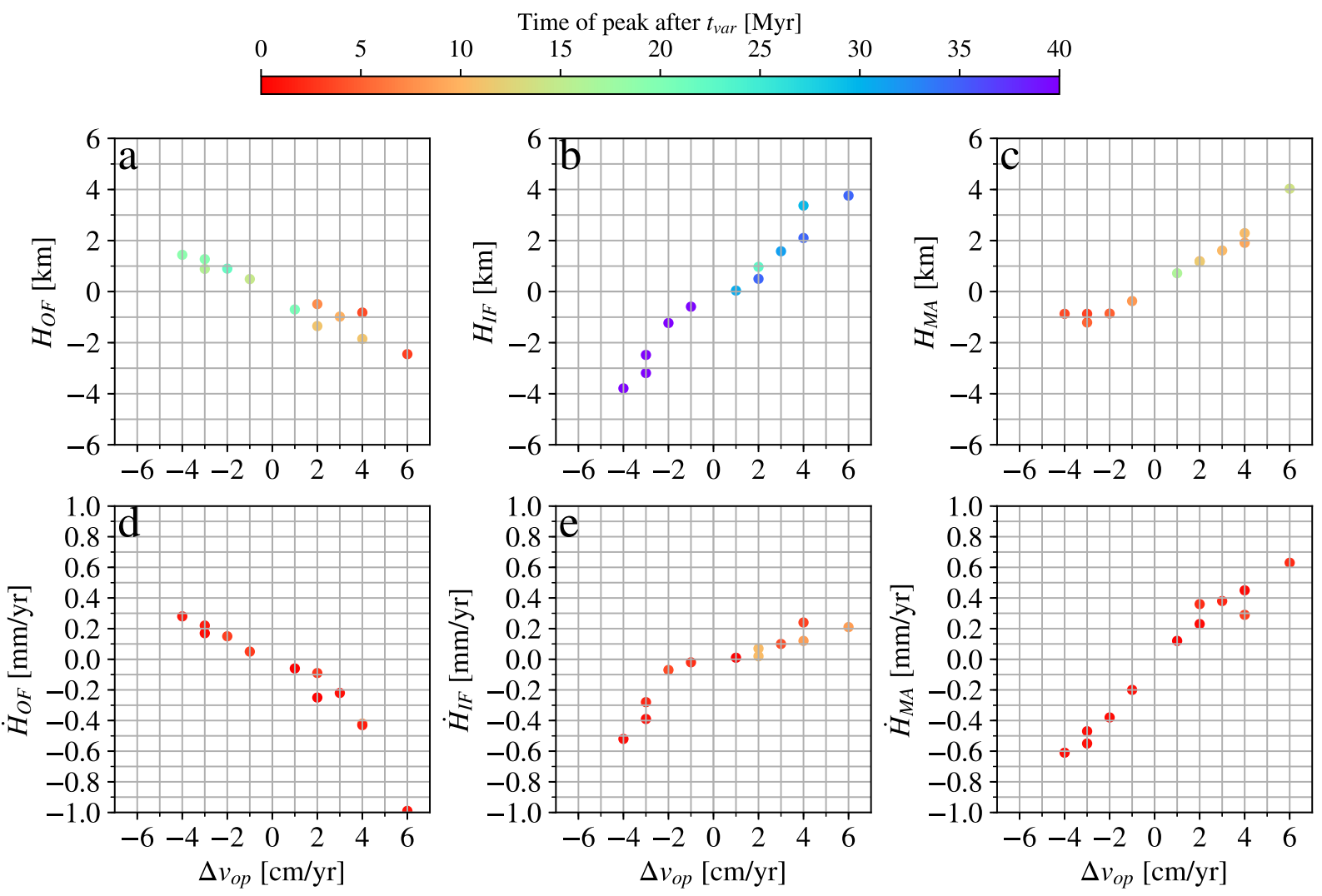

Figure S4. Value of the peaks in displacement (first row) and elevation change (second row) of the three characteristic points as of $t=\left.t_{\text {var }} O F\right|_{t_{v a r}}$ (first column), IF $\left.\right|_{t_{v a r}}$ (second column), and $\left.M A\right|_{t_{v a r}}$ (third column), for models at reference rheological parameters undergoing a sudden change in OP-velocity. The color represent the time $t-t_{v a r}$ at which the peaks are reached relative to the time of $\mathrm{OP}$-velocity variation. 

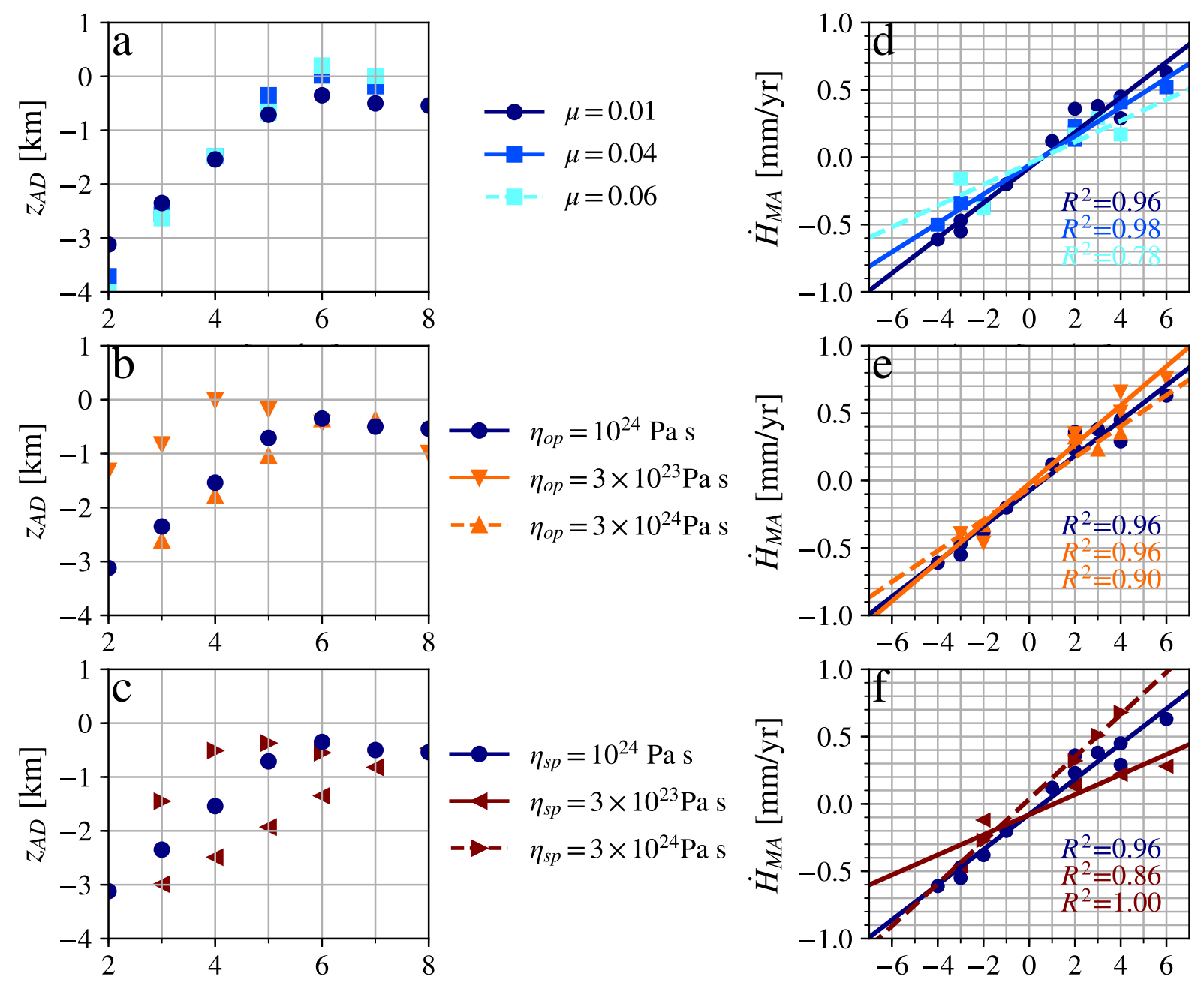

Figure S5. Steady-state elevation of the arc depression with constant OP velocity (a,b,c) and rate of elevation change in the mid-arc with the value of change in OP velocity $(d, e, f)$ for set of models with various OP viscosity (first row), SP viscosity (second row), and interplate friction (third row). For other legend details see Figs. 5 and 8 in the main text. 

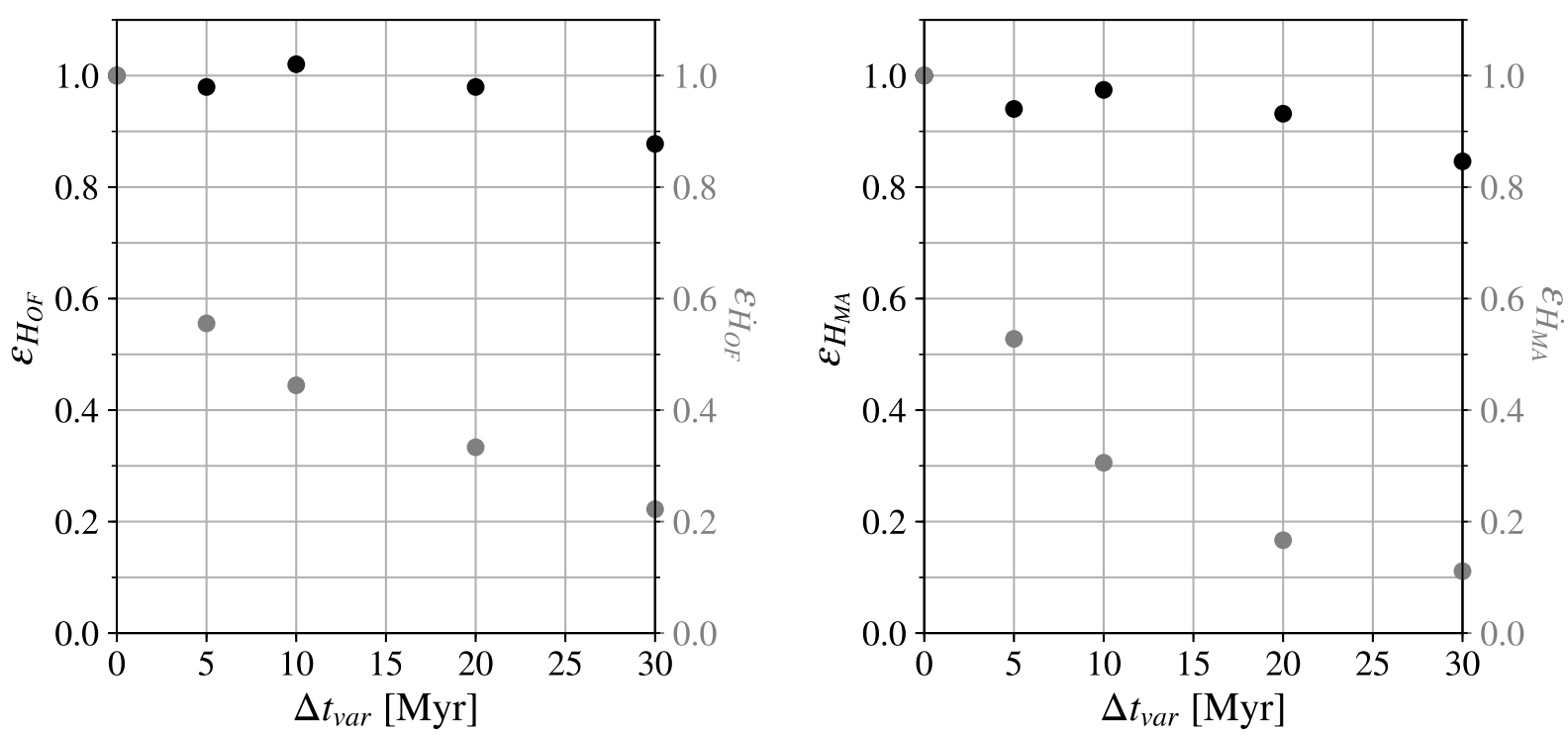

Figure S6. Relative maximum vertical displacement $H$ and relative maximum rate of elevation change $\dot{H}$ of points $\left.O F\right|_{t_{v a r}}$ and $\left.M A\right|_{t_{v a r}}$ after an increase in OP velocity from 4 to $6 \mathrm{~cm} / \mathrm{yr}$ plotted against the time $\Delta t_{v a r}$ over which the OP evolves (linearly). The values are expressed relative to their values obtained with $\Delta t_{\text {var }}=0$. 
Table S1: Model name and main model parameters.

\begin{tabular}{|c|c|c|c|c|c|c|c|}
\hline Models & $\begin{array}{c}\eta_{s p} \\
{[\mathrm{~Pa} s]}\end{array}$ & $\begin{array}{c}\eta_{o p} \\
{[\mathrm{~Pa} s]}\end{array}$ & $\mu$ & $\begin{array}{c}v_{o p_{1}} \\
{[\mathrm{~cm} / \mathrm{yr}]}\end{array}$ & $\begin{array}{c}v_{o p_{2}} \\
{[\mathrm{~cm} / \mathrm{yr}]} \\
\end{array}$ & $\begin{array}{c}t_{v a r} \\
{[\mathrm{Myr}]}\end{array}$ & $\begin{array}{l}\Delta t_{\text {var }} \\
{[\mathrm{Myr}]} \\
\end{array}$ \\
\hline $\mathrm{A} 2$ & $10^{24}$ & $10^{24}$ & 0.01 & 2.0 & & & \\
\hline A3 & $10^{24}$ & $10^{24}$ & 0.01 & 3.0 & & & \\
\hline $\mathrm{A} 4$ & $10^{24}$ & $10^{24}$ & 0.01 & 4.0 & & & \\
\hline A5 & $10^{24}$ & $10^{24}$ & 0.01 & 5.0 & & & \\
\hline A 6 & $10^{24}$ & $10^{24}$ & 0.01 & 6.0 & & & \\
\hline A 7 & $10^{24}$ & $10^{24}$ & 0.01 & 7.0 & & & \\
\hline A 8 & $10^{24}$ & $10^{24}$ & 0.01 & 8.0 & & & \\
\hline A2_3 & $10^{24}$ & $10^{24}$ & 0.01 & 2.0 & 3.0 & 65.0 & 0.0 \\
\hline A2_ 4 & $10^{24}$ & $10^{24}$ & 0.01 & 2.0 & 4.0 & 65.0 & 0.0 \\
\hline A2_6 & $10^{24}$ & $10^{24}$ & 0.01 & 2.0 & 6.0 & 65.0 & 0.0 \\
\hline A2_8 & $10^{24}$ & $10^{24}$ & 0.01 & 2.0 & 8.0 & 65.0 & 0.0 \\
\hline A3_6 & $10^{24}$ & $10^{24}$ & 0.01 & 3.0 & 6.0 & 60.0 & 0.0 \\
\hline A4_6 & $10^{24}$ & $10^{24}$ & 0.01 & 4.0 & 6.0 & 55.0 & 0.0 \\
\hline A4_8 & $10^{24}$ & $10^{24}$ & 0.01 & 4.0 & 8.0 & 55.0 & 0.0 \\
\hline A3_2 & $10^{24}$ & $10^{24}$ & 0.01 & 3.0 & 2.0 & 60.0 & 0.0 \\
\hline $\mathrm{A} 4 \_2$ & $10^{24}$ & $10^{24}$ & 0.01 & 4.0 & 2.0 & 55.0 & 0.0 \\
\hline A5_2 & $10^{24}$ & $10^{24}$ & 0.01 & 5.0 & 2.0 & 50.0 & 0.0 \\
\hline A6_3 & $10^{24}$ & $10^{24}$ & 0.01 & 6.0 & 3.0 & 45.0 & 0.0 \\
\hline A6_2 & $10^{24}$ & $10^{24}$ & 0.01 & 6.0 & 2.0 & 45.0 & 0.0 \\
\hline A4_6_5 & $10^{24}$ & $10^{24}$ & 0.01 & 4.0 & 6.0 & 55.0 & 5.0 \\
\hline A4_6_10 & $10^{24}$ & $10^{24}$ & 0.01 & 4.0 & 6.0 & 55.0 & 10.0 \\
\hline A4_6_20 & $10^{24}$ & $10^{24}$ & 0.01 & 4.0 & 6.0 & 55.0 & 20.0 \\
\hline A4_6_30 & $10^{24}$ & $10^{24}$ & 0.01 & 4.0 & 6.0 & 55.0 & 30.0 \\
\hline $\mathrm{B} 2$ & $10^{24}$ & $10^{24}$ & 0.04 & 2.0 & & & \\
\hline B3 & $10^{24}$ & $10^{24}$ & 0.04 & 3.0 & & & \\
\hline B4 & $10^{24}$ & $10^{24}$ & 0.04 & 4.0 & & & \\
\hline B5 & $10^{24}$ & $10^{24}$ & 0.04 & 5.0 & & & \\
\hline B6 & $10^{24}$ & $10^{24}$ & 0.04 & 6.0 & & & \\
\hline B7 & $10^{24}$ & $10^{24}$ & 0.04 & 7.0 & & & \\
\hline B2_4 & $10^{24}$ & $10^{24}$ & 0.04 & 2.0 & 4.0 & 65.0 & 0.0 \\
\hline B2_6 & $10^{24}$ & $10^{24}$ & 0.04 & 2.0 & 6.0 & 65.0 & 0.0 \\
\hline B2_8 & $10^{24}$ & $10^{24}$ & 0.04 & 2.0 & 8.0 & 65.0 & 0.0 \\
\hline B3_6 & $10^{24}$ & $10^{24}$ & 0.04 & 3.0 & 6.0 & 60.0 & 0.0 \\
\hline B4_6 & $10^{24}$ & $10^{24}$ & 0.04 & 4.0 & 6.0 & 55.0 & 0.0 \\
\hline B4_2 & $10^{24}$ & $10^{24}$ & 0.04 & 4.0 & 2.0 & 55.0 & 0.0 \\
\hline B6_3 & $10^{24}$ & $10^{24}$ & 0.04 & 6.0 & 3.0 & 45.0 & 0.0 \\
\hline B6_2 & $10^{24}$ & $10^{24}$ & 0.04 & 6.0 & 2.0 & 45.0 & 0.0 \\
\hline $\mathrm{C} 2$ & $10^{24}$ & $3 \times 10^{23}$ & 0.01 & 2.0 & & & \\
\hline C3 & $10^{24}$ & $3 \times 10^{23}$ & 0.01 & 3.0 & & & \\
\hline $\mathrm{C} 4$ & $10^{24}$ & $3 \times 10^{23}$ & 0.01 & 4.0 & & & \\
\hline C5 & $10^{24}$ & $3 \times 10^{23}$ & 0.01 & 5.0 & & & \\
\hline C6 & $10^{24}$ & $3 \times 10^{23}$ & 0.01 & 6.0 & & & \\
\hline $\mathrm{C} 8$ & $10^{24}$ & $3 \times 10^{23}$ & 0.01 & 8.0 & & & \\
\hline $\mathrm{C} 2 \_4$ & $10^{24}$ & $3 \times 10^{23}$ & 0.01 & 2.0 & 4.0 & 65.0 & 0.0 \\
\hline $\mathrm{C} 2 \_6$ & $10^{24}$ & $3 \times 10^{23}$ & 0.01 & 2.0 & 6.0 & 65.0 & 0.0 \\
\hline $\mathrm{C} 2 \_8$ & $10^{24}$ & $3 \times 10^{23}$ & 0.01 & 2.0 & 8.0 & 65.0 & 0.0 \\
\hline $\mathrm{C} 4 \_2$ & $10^{24}$ & $3 \times 10^{23}$ & 0.01 & 4.0 & 2.0 & 55.0 & 0.0 \\
\hline $\mathrm{C} 4 \_6$ & $10^{24}$ & $3 \times 10^{23}$ & 0.01 & 4.0 & 6.0 & 55.0 & 0.0 \\
\hline C4_8 & $10^{24}$ & $3 \times 10^{23}$ & 0.01 & 4.0 & 8.0 & 55.0 & 0.0 \\
\hline C6_3 & $10^{24}$ & $3 \times 10^{23}$ & 0.01 & 6.0 & 3.0 & 45.0 & 0.0 \\
\hline D2 & $3 \times 10^{23}$ & $10^{24}$ & 0.01 & 2.0 & & & \\
\hline D3 & $3 \times 10^{23}$ & $10^{24}$ & 0.01 & 3.0 & & & \\
\hline D4 & $3 \times 10^{23}$ & $10^{24}$ & 0.01 & 4.0 & & & \\
\hline D5 & $3 \times 10^{23}$ & $10^{24}$ & 0.01 & 5.0 & & & \\
\hline D6 & $3 \times 10^{23}$ & $10^{24}$ & 0.01 & 6.0 & & & \\
\hline D7 & $3 \times 10^{23}$ & $10^{24}$ & 0.01 & 7.0 & & & \\
\hline D8 & $3 \times 10^{23}$ & $10^{24}$ & 0.01 & 8.0 & & & \\
\hline D2_4 & $3 \times 10^{23}$ & $10^{24}$ & 0.01 & 2.0 & 4.0 & 65.0 & 0.0 \\
\hline D2_8 & $3 \times 10^{23}$ & $10^{24}$ & 0.01 & 2.0 & 8.0 & 65.0 & 0.0 \\
\hline D4_6 & $3 \times 10^{23}$ & $10^{24}$ & 0.01 & 4.0 & 6.0 & 55.0 & 0.0 \\
\hline D4_8 & $3 \times 10^{23}$ & $10^{24}$ & 0.01 & 4.0 & 6.0 & 55.0 & 0.0 \\
\hline D4_2 & $3 \times 10^{23}$ & $10^{24}$ & 0.01 & 4.0 & 2.0 & 55.0 & 0.0 \\
\hline D6_3 & $3 \times 10^{23}$ & $10^{24}$ & 0.01 & 6.0 & 3.0 & 45.0 & 0.0 \\
\hline E3 & $10^{24}$ & $3 \times 10^{24}$ & 0.01 & 3.0 & & & \\
\hline $\mathrm{E} 4$ & $10^{24}$ & $3 \times 10^{24}$ & 0.01 & 4.0 & & & \\
\hline E5 & $10^{24}$ & $3 \times 10^{24}$ & 0.01 & 5.0 & & & \\
\hline E6 & $10^{24}$ & $3 \times 10^{24}$ & 0.01 & 6.0 & & & \\
\hline
\end{tabular}

February 27, 2020, 5:58pm 
$\mathrm{X}-14$

\begin{tabular}{|c||c|c|c|c|c|c|c|} 
E7 & $10^{24}$ & $3 \times 10^{24}$ & 0.01 & 7.0 & & & \\
E3_6 & $10^{24}$ & $3 \times 10^{24}$ & 0.01 & 3.0 & 6.0 & 60.0 & 0.0 \\
E4_2 & $10^{24}$ & $3 \times 10^{24}$ & 0.01 & 4.0 & 2.0 & 55.0 & 0.0 \\
E4_6 & $10^{24}$ & $3 \times 10^{24}$ & 0.01 & 4.0 & 6.0 & 55.0 & 0.0 \\
E4_8 & $10^{24}$ & $3 \times 10^{24}$ & 0.01 & 4.0 & 8.0 & 55.0 & 0.0 \\
\hline F3 & $3 \times 10^{24}$ & $10^{24}$ & 0.01 & 3.0 & & & \\
F4 & $3 \times 10^{24}$ & $10^{24}$ & 0.01 & 4.0 & & & \\
F5 & $3 \times 10^{24}$ & $10^{24}$ & 0.01 & 5.0 & & & \\
F6 & $3 \times 10^{24}$ & $10^{24}$ & 0.01 & 6.0 & & & \\
F3_6 & $3 \times 10^{24}$ & $10^{24}$ & 0.01 & 3.0 & 6.0 & 60.0 & 0.0 \\
F4_2 & $3 \times 10^{24}$ & $10^{24}$ & 0.01 & 4.0 & 2.0 & 55.0 & 0.0 \\
F4_6 & $3 \times 10^{24}$ & $10^{24}$ & 0.01 & 4.0 & 6.0 & 55.0 & 0.0 \\
F4_8 & $3 \times 10^{24}$ & $10^{24}$ & 0.01 & 4.0 & 6.0 & 55.0 & 0.0 \\
\hline G2 & $10^{24}$ & $10^{24}$ & 0.06 & 2.0 & & & \\
G3 & $10^{24}$ & $10^{24}$ & 0.06 & 3.0 & & & \\
G4 & $10^{24}$ & $10^{24}$ & 0.06 & 4.0 & & & \\
G5 & $10^{24}$ & $10^{24}$ & 0.06 & 5.0 & & & \\
G6 & $10^{24}$ & $10^{24}$ & 0.06 & 6.0 & & & \\
G7 & $10^{24}$ & $10^{24}$ & 0.06 & 7.0 & & & \\
G3_6 & $10^{24}$ & $10^{24}$ & 0.06 & 3.0 & 6.0 & 60.0 & 0.0 \\
G4_2 & $10^{24}$ & $10^{24}$ & 0.06 & 4.0 & 2.0 & 55.0 & 0.0 \\
G4_6 & $10^{24}$ & $10^{24}$ & 0.06 & 4.0 & 6.0 & 55.0 & 0.0 \\
G4_8 & $10^{24}$ & $10^{24}$ & 0.06 & 4.0 & 8.0 & 55.0 & 0.0 \\
G6_3 & $10^{24}$ & $10^{24}$ & 0.06 & 6.0 & 3.0 & 45.0 & 0.0 \\
\hline
\end{tabular}

February 27, 2020, 5:58pm 